\title{
Atomic data from the Iron Project. XVII. Radiative transition probabilities for dipole allowed and forbidden transitions in Fe III
}

\author{
S.N. Nahar and A.K. Pradhan \\ Department of Astronomy, The Ohio State University, Columbus, OH 43210, U.S.A. \\ Internet: nahar@payne.mps.ohio-state.edu, pradhan@payne.mps.ohio-state.edu \\ Received January 17, 1995; accepted March 14, 1996
}

\begin{abstract}
Transition probabilities are obtained for both the dipole allowed (E1) fine structure transitions and the forbidden electric quadrupole and magnetic dipole (E2, M1) transitions in Fe III. For the E1 transitions, ab initio calculations in the close coupling (CC) approximation using the R-matrix method are carried out in LS coupling with a 49-term eigenfunction expansion for Fe IV. The fine structure components are obtained through algebraic transformation of the LS line strengths, and the oscillator strengths and $A$-coefficients are computed using spectroscopic energies of the observed levels. Radiative transition probabilities for 9797 fine structure E1 transitions corresponding to 1408 LS multiplets among 200 bound states of Fe III are reported. Forbidden E2 and M1 transition probabilities are computed for 362 transitions among the 34 fine structure levels of all 16 LS terms dominated by the $3 \mathrm{~d}^{6}$ configuration using optimised configuration-interaction wavefunctions from the SUPERSTRUCTURE program in the Breit-Pauli approximation. Comparison of the present results is made with previous calculations and significant differences are found. Theoretical line ratios computed using the present E2 and M1 A-coefficients show better agreement with observations for some prominent Fe III lines in the infra-red than those using the earlier data by Garstang (1957). This work is carried out as part of the Iron Project to obtain accurate radiative and collisional data for the Iron group elements. ${ }^{\star}$
\end{abstract}

Key words: atomic data — plasmas — ultraviolet: general — infrared: general — optical

\section{Introduction}

The spectrum of Fe III is prominently observed from a variety of astrophysical objects such as diffuse and planetary nebulae, supernova remnants, the Galactic Center, and Herbig-Haro objects. However, very little of the currently available atomic data is of sufficient precision to enable accurate spectral diagnostics. In a program under the auspices of the Iron Project (Hummer et al. 1993) we have recently completed extensive new calculations for radiative and collisional atomic processes for Fe III, including photoionization (Nahar 1996, N1), e+ion recombination (Nahar 1996), radiative transition probabilities (this paper), and collision strengths and rate coefficients (Zhang \& Pradhan 1995; Zhang 1996, the following paper). The aim is to compute essentially all atomic data needed to construct an extended Non-LTE collisional-radiative model

Send offprint requests to: S.N. Nahar

${ }^{\star}$ The complete table of dipole allowed transition probabilities is available in electronic form at the CDS via anonymous ftp 130.79.128.5 of line emissivities, including ionization balance, and to apply the model for spectral diagnostics of Fe III spectra from different astrophysical sources. Previous or concurrent work deal with Fe II (Nahar 1994; Zhang \& Pradhan 1994), and Fe I (Bautista \& Pradhan 1995; Bautista 1996).

The relative complexity of the Fe III ion makes it rather difficult to carry out ab initio calculations for the atomic parameters. Previous calculations for the transition probabilities for Fe III have been carried out mainly employing different versions of the semi-empirical atomic structure code by Cowan (1968); the investigators include Kurucz \& Peytremann (1975), Biemont (1976), Fawcett (1989), and most recently Ekberg (1993). The first ab initio calculations for the radiative data, oscillator strengths and photoionization cross sections, for Fe III was carried out by Sawey \& Berrington (1992) under the Opacity Project (OP) (Seaton 1987) using the R-matrix method and a close coupling $(\mathrm{CC})$ eigenfunction expansion dominated by the ground configuration $3 \mathrm{~d}^{5}$ only of Fe IV. However, as discussed by Nahar (1996, N1), this expansion neglects the important electron correlation effects due to 
Table 1. Comparison of the present calculated, E(cal), and the observed, E(obs) (Sugar \& Corliss 1985 ; Ekberg 1993 as indicated by Ek), absolute energies (in Rydbergs) of Fe III. An * next to a state indicates an incomplete set of observed fine structure levels for the state. Each state is assigned with a degeneracy symbol as explained in the text

\begin{tabular}{|c|c|c|c|c|c|c|c|}
\hline configuration & $\mathrm{SL} \pi$ & $E(\mathrm{obs})$ & $E(\mathrm{cal})$ & configuration & $\mathrm{SL} \pi$ & $E(\mathrm{obs})$ & $E(\mathrm{cal})$ \\
\hline $3 d^{5}{ }^{6} S 4 s$ & $a^{7} S^{e}$ & 1.97864 & 1.928 & $3 d^{5}{ }^{6} S 4 p$ & $z^{7} P^{o}$ & 1.50127 & 1.485 \\
\hline $3 d^{5}{ }^{6} S 4 d$ & $a^{7} D^{e}$ & 0.91033 & 0.893 & $3 d^{5}{ }^{6} S 5 s$ & $b^{7} S^{e}$ & 0.89244 & 0.884 \\
\hline $3 d^{5}{ }^{6} S 5 p$ & $y^{7} P^{o}$ & 0.73740 & 0.726 & $3 d^{5}{ }^{6} S 4 f$ & $z^{7} F^{o} *$ & 0.57272 & 0.575 \\
\hline $3 d^{4} D 4 s 4 p^{3} P^{o}$ & $x^{7} P^{o}$ & 0.54930 & 0.560 & $3 d^{5}{ }^{6} S 5 d$ & $b^{7} D^{e}$ & 0.51767 & 0.511 \\
\hline $3 d^{5}{ }^{6} S 6 s$ & $c^{7} S^{e}$ & 0.51306 & 0.510 & $3 d^{5}{ }^{6} S 6 p$ & $w^{7} P^{o}$ & 0.44233 & 0.437 \\
\hline $3 d^{5}{ }^{6} S 5 f$ & $y^{7} F^{o} *$ & 0.36542 & 0.364 & $3 d^{5}{ }^{6} S 5 g$ & $a^{7} G^{e} *$ & 0.36067 & 0.360 \\
\hline $3 d^{5}{ }^{6} S 6 d$ & $c^{7} D^{e}$ & 0.33549 & 0.332 & $3 d^{5}{ }^{6} S 7 s$ & $d^{7} S^{e}$ & 0.33356 & 0.332 \\
\hline $3 d^{5}{ }^{6} S 6 g$ & $b^{7} G^{e} *$ & 0.25041 & 0.250 & $3 d^{5}{ }^{6} S 6 h$ & $z^{7} H^{o} *$ & 0.25005 & 0.250 \\
\hline $3 d^{6}$ & $a^{5} D^{e}$ & 2.24898 & 2.127 & $3 d^{5}{ }^{6} S 4 s$ & $a^{5} S^{e}$ & 1.87921 & 1.828 \\
\hline $3 d^{5}{ }^{4} G 4 s$ & $a^{5} G^{e}$ & 1.67448 & 1.586 & $3 d^{54} P 4 s$ & $a^{5} P^{e}$ & 1.64675 & 1.582 \\
\hline $3 d^{54} D 4 s$ & $b^{5} D^{e}$ & 1.61698 & 1.532 & $3 d^{54} F 4 s$ & $a^{5} F^{e}$ & 1.49430 & 1.407 \\
\hline $3 d^{5}{ }^{6} S 4 p$ & $z^{5} P^{o}$ & 1.43953 & 1.421 & $3 d^{5}{ }^{4} G 4 p$ & $z^{5} G^{o}$ & 1.21704 & 1.148 \\
\hline $3 d^{5}{ }^{4} G 4 p$ & $z^{5} H^{o}$ & 1.20162 & 1.137 & $3 d^{5}{ }^{4} G 4 p$ & $z^{5} F^{o}$ & 1.19089 & 1.122 \\
\hline $3 d^{5}{ }^{4} P 4 p$ & $z^{5} S^{o}$ & 1.18758 & 1.137 & $3 d^{5}{ }^{4} P 4 p$ & $z^{5} D^{o}$ & 1.18673 & 1.136 \\
\hline $3 d^{54} P 4 p$ & $y^{5} P^{o}$ & 1.17188 & 1.119 & $3 d^{54} D 4 p$ & $y^{5} F^{o}$ & 1.14874 & 1.075 \\
\hline $3 d^{54} D 4 p$ & $y^{5} D^{o}$ & $1.13378 \mathrm{Ek}$ & 1.060 & $3 d^{5}{ }^{4} D 4 p$ & $x^{5} P^{o}$ & 1.12566 & 1.056 \\
\hline $3 d^{54} F 4 p$ & $y^{5} G^{o}$ & 1.01894 & 0.940 & $3 d^{5}{ }^{4} F 4 p$ & $x^{5} F^{o}$ & 1.01264 & 0.930 \\
\hline $3 d^{54} F 4 p$ & $x^{5} D^{o}$ & 1.00081 & 0.919 & $3 d^{5}{ }^{6} S 4 d$ & $c^{5} D^{e}$ & 0.87193 & 0.853 \\
\hline $3 d^{5}{ }^{6} S 5 s$ & $b^{5} S^{e}$ & 0.86991 & 0.860 & $3 d^{5}{ }^{6} S 5 p$ & $w^{5} P^{o}$ & 0.71835 & 0.708 \\
\hline $3 d^{54} G 4 d$ & $a^{5} H^{e}$ & 0.61977 & 0.574 & $3 d^{54} G 4 d$ & $b^{5} F^{e}$ & 0.61590 & 0.571 \\
\hline $3 d^{54} G 4 d$ & $b^{5} G^{e}$ & 0.61486 & 0.569 & $3 d^{5}{ }^{4} G 4 d$ & $a^{5} I^{e}$ & 0.61351 & 0.570 \\
\hline $3 d^{5}{ }^{4} G 5 s$ & $c^{5} G^{e}$ & 0.59608 & 0.586 & $3 d^{5}{ }^{4} P 4 d$ & $c^{5} F^{e}$ & 0.59045 & 0.555 \\
\hline $3 d^{5}{ }^{6} S 4 f$ & $w^{5} F^{o}$ & 0.56900 & 0.565 & $3 d^{5}{ }^{4} P 5 s$ & $b^{5} P^{e}$ & 0.56707 & 0.559 \\
\hline $3 d^{5}{ }^{4} D 4 d$ & $d^{5} G^{e}$ & 0.55390 & 0.510 & $3 d^{5}{ }^{4} D 4 d$ & $d^{5} D^{e} *$ & 0.54980 & 0.506 \\
\hline $3 d^{54} D 5 s$ & $e^{5} D^{e}$ & 0.53888 & 0.526 & $3 d^{5}{ }^{6} S 6 s$ & $c^{5} S^{e}$ & 0.50313 & 0.498 \\
\hline $3 d^{5 \quad 6} S 5 d$ & $f^{5} D^{e}$ & 0.48854 & 0.462 & $3 d^{54} G 5 p$ & $x^{5} G^{o}$ & 0.44546 & 0.431 \\
\hline $3 d^{5}{ }^{4} G 5 p$ & $y^{5} H^{o}$ & 0.44140 & 0.428 & $3 d^{5}{ }^{4} G 5 p$ & $v^{5} F^{o}$ & 0.43738 & 0.424 \\
\hline $3 d^{5 \quad} F 4 d$ & $b^{5} H^{e}$ & 0.43134 & 0.379 & $3 d^{5}{ }^{4} F 4 d$ & $e^{5} G^{e}$ & 0.42611 & 0.378 \\
\hline $3 d^{5}{ }^{4} P 5 p$ & $w^{5} D^{o}$ & 0.41952 & 0.402 & $3 d^{5}{ }^{4} P 5 p$ & $y^{5} S^{o}$ & 0.41851 & 0.404 \\
\hline $3 d^{54} F 5 s$ & $d^{5} F^{e}$ & 0.41197 & 0.400 & $3 d^{54} P 5 p$ & $v^{5} P^{o}$ & 0.40975 & 0.399 \\
\hline $3 d^{54} D 5 p$ & $u^{5} F^{o}$ & 0.38410 & 0.369 & $3 d^{5}{ }^{4} D 5 p$ & $v^{5} D^{\circ} *$ & 0.37830 & 0.366 \\
\hline $3 d^{5}{ }^{6} S 5 f$ & $t^{5} F^{o}$ & 0.36408 & 0.362 & $3 d^{5}{ }^{6} S 5 g$ & $f^{5} G^{e}$ & 0.36065 & 0.360 \\
\hline $3 d^{5}{ }^{4} F 5 p$ & $w^{5} G^{o}$ & 0.25676 & 0.243 & $3 d^{5}{ }^{4} F 5 p$ & $s^{5} F^{o}$ & 0.25239 & 0.243 \\
\hline $3 d^{56} S 6 g$ & $g^{5} G^{e}$ & 0.25039 & 0.250 & $3 d^{5}{ }^{6} S 6 h$ & $x^{5} H^{o} *$ & 0.25004 & 0.250 \\
\hline $3 d^{54} G 5 d$ & $c^{5} H^{e}$ & 0.22433 & 0.210 & $3 d^{54} G 5 d$ & $e^{5} F^{e}$ & 0.22311 & 0.209 \\
\hline $3 d^{54} G 5 d$ & $h^{5} G^{e}$ & 0.22303 & 0.209 & $3 d^{5}{ }^{4} G 5 d$ & $b^{5} I^{e}$ & 0.22234 & 0.209 \\
\hline $3 d^{5}{ }^{4} G 6 s$ & $i^{5} G^{e}$ & 0.21790 & 0.214 & $3 d^{5}{ }^{4} P 6 s$ & $c^{5} P^{e}$ & 0.18946 & 0.187 \\
\hline $3 d^{5}{ }^{4} D 6 s$ & $g^{5} D^{e} *$ & 0.16155 & 0.154 & $3 d^{6}$ & $a^{3} P^{e} 2$ & 2.07027 & 1.952 \\
\hline $3 d^{6}$ & $a^{3} H^{e}$ & 2.06828 & 1.920 & $3 d^{6}$ & $a^{3} F^{e} 2$ & 2.05567 & 1.926 \\
\hline $3 d^{6}$ & $a^{3} G^{e}$ & 2.02649 & 1.885 & $3 d^{6}$ & $a^{3} D^{e}$ & 1.97230 & 1.840 \\
\hline $3 d^{6}$ & $b^{3} P^{e} 1$ & 1.79726 & 1.665 & $3 d^{6}$ & $b^{3} F^{e} 1$ & 1.79482 & 1.656 \\
\hline $3 d^{5 \quad} G 4 s$ & $b^{3} G^{e}$ & 1.60844 & 1.511 & $3 d^{54} P 4 s$ & $c^{3} P^{e}$ & 1.58039 & 1.508 \\
\hline $3 d^{5}{ }^{4} D 4 s$ & $b^{3} D^{e}$ & 1.55089 & 1.460 & $3 d^{52} I 4 s$ & $a^{3} I^{e}$ & 1.52521 & 1.405 \\
\hline $3 d^{52} D_{3} 4 s$ & $c^{3} D^{e}$ & 1.50181 & 1.416 & $3 d^{5}{ }^{2} F_{2} 4 s$ & $c^{3} F^{e}$ & 1.48390 & 1.400 \\
\hline $3 d^{52} H 4 s$ & $b^{3} H^{e}$ & 1.44384 & 1.339 & $3 d^{52} G_{2} 4 s$ & $c^{3} G^{e}$ & 1.43440 & 1.322 \\
\hline $3 d^{5}{ }^{4} F 4 s$ & $d^{3} F^{e}$ & 1.42845 & 1.334 & $3 d^{5}{ }^{2} F_{1} 4 s$ & $e^{3} F^{e}$ & 1.40174 & 1.297 \\
\hline $3 d^{52} S 4 s$ & $a^{3} S^{e}$ & 1.35375 & 1.250 & $3 d^{5}{ }^{2} D_{2} 4 s$ & $d^{3} D^{e}$ & 1.28766 & 1.186 \\
\hline $3 d^{52} G_{1} 4 s$ & $d^{3} G^{e}$ & 1.21091 & 1.090 & $3 d^{5}{ }^{4} G 4 p$ & $z^{3} F^{o}$ & 1.17506 & 1.127 \\
\hline $3 d^{5}{ }^{4} G 4 p$ & $z^{3} H^{o}$ & 1.17286 & 1.127 & $3 d^{5}{ }^{4} P 4 p$ & $z^{3} P^{o}$ & 1.16071 & 1.132 \\
\hline $3 d^{54} G 4 p$ & $z^{3} G^{o}$ & 1.14164 & 1.090 & $3 d^{5}{ }^{4} P 4 p$ & $z^{3} D^{o}$ & 1.13616 & 1.108 \\
\hline $3 d^{54} D 4 p$ & $y^{3} D^{o}$ & 1.11474 & 1.070 & $3 d^{5}{ }^{4} D 4 p$ & $y^{3} F^{o}$ & 1.10862 & 1.061 \\
\hline $3 d^{5}{ }^{4} P 4 p$ & $z^{3} S^{o}$ & 1.10107 & 1.069 & $3 d^{5}{ }^{4} D 4 p$ & $y^{3} P^{o}$ & 1.07955 & 1.028 \\
\hline $3 d^{52} I 4 p$ & $z^{3} K^{o}$ & 1.06551 & 0.998 & $3 d^{52} I 4 p$ & $z^{3} I^{o}$ & 1.06160 & 0.993 \\
\hline $3 d^{52} P 4 s$ & $d^{3} P^{e}$ & $1.06035 \mathrm{Ek}$ & 0.943 & $3 d^{5} a^{2} D 4 p$ & $x^{3} F^{o}$ & 1.04642 & 1.007 \\
\hline $3 d^{52} I 4 p$ & $y^{3} H^{o}$ & 1.04566 & 0.973 & $3 d^{5} a^{2} D 4 p$ & $x^{3} P^{o}$ & 1.02762 & 0.981 \\
\hline $3 d^{5} a^{2} F 4 p$ & $y^{3} G^{o}$ & 1.02083 & 0.978 & $3 d^{5} a^{2} D 4 p$ & $x^{3} D^{o}$ & 1.02148 & 0.974 \\
\hline $3 d^{5} a^{2} F 4 p$ & $w^{3} D^{o}$ & 1.01150 & 0.963 & $3 d^{5} a^{2} F 4 p$ & $w^{3} F^{o}$ & 1.00754 & 0.967 \\
\hline $3 d^{5}{ }^{2} H 4 p$ & $x^{3} H^{o}$ & 0.99622 & 0.938 & $3 d^{52} H 4 p$ & $x^{3} G^{o}$ & 0.99432 & 0.945 \\
\hline $3 d^{5} c^{2} D 4 s$ & $e^{3} D^{e}$ & $0.98731 \mathrm{Ek}$ & 0.872 & $3 d^{5}{ }^{4} F 4 p$ & $w^{3} G^{o}$ & 0.98094 & 0.923 \\
\hline $3 d^{52} H 4 p$ & $y^{3} I^{o}$ & 0.97810 & 0.927 & $3 d^{5} a^{2} G 4 p$ & $v^{3} F^{o}$ & 0.96940 & 0.913 \\
\hline $3 d^{5}{ }^{4} F 4 p$ & $v^{3} D^{o}$ & 0.96389 & 0.912 & $3 d^{5}{ }^{4} F 4 p$ & $u^{3} F^{o}$ & 0.95654 & 0.892 \\
\hline $3 d^{5} a^{2} G 4 p$ & $w^{3} H^{o}$ & 0.94920 & 0.885 & $3 d^{5} a^{2} G 4 p$ & $v^{3} G^{o}$ & 0.94050 & 0.874 \\
\hline $3 d^{5} b^{2} F 4 p$ & $t^{3} F^{o}$ & 0.93400 & 0.861 & $3 d^{5} b^{2} F 4 p$ & $u^{3} G^{o}$ & 0.91153 & 0.846 \\
\hline
\end{tabular}


Table 1. continued

\begin{tabular}{|c|c|c|c|c|c|c|c|}
\hline configuration & $\mathrm{SL} \pi$ & $E(\mathrm{obs})$ & $E(\mathrm{cal})$ & configuration & $\mathrm{SL} \pi$ & $E(\mathrm{obs})$ & $E(\mathrm{cal})$ \\
\hline $3 d^{5} b^{2} F 4 p$ & $u^{3} D^{o}$ & 0.90768 & 0.841 & $3 d^{52} S 4 p$ & $w^{3} P^{o}$ & 0.89299 & 0.825 \\
\hline $3 d^{5} b^{2} D 4 p$ & $s^{3} F^{o}$ & 0.81157 & 0.746 & $3 d^{5} b^{2} D 4 p$ & $t^{3} D^{o}$ & 0.80819 & 0.748 \\
\hline $3 d^{5} b^{2} D 4 p$ & $v^{3} P^{o}$ & $0.79434 \mathrm{Ek}$ & 0.723 & $3 d^{5} b^{2} G 4 p$ & $v^{3} H^{o}$ & 0.74034 & 0.664 \\
\hline $3 d^{5} b^{2} G 4 p$ & $r^{3} F^{o}$ & 0.73557 & 0.657 & $3 d^{5} b^{2} G 4 p$ & $t^{3} G^{o}$ & 0.72907 & 0.652 \\
\hline $3 d^{52} P 4 p$ & $u^{3} P^{o}$ & $0.62122 \mathrm{Ek}$ & 0.544 & $3 d^{5}{ }^{4} G 4 d$ & $f^{3} F^{e}$ & 0.59060 & 0.520 \\
\hline $3 d^{5}{ }^{4} G 4 d$ & $b^{3} I^{e}$ & 0.58673 & 0.537 & $3 d^{52} P 4 p$ & $s^{3} D^{o}$ & $0.58526 \mathrm{Ek}$ & 0.500 \\
\hline $3 d^{5}{ }^{4} G 5 s$ & $e^{3} G^{e}$ & 0.58114 & 0.568 & $3 d^{52} P 4 p$ & $y^{3} S^{o}$ & $0.56596 \mathrm{Ek}$ & 0.476 \\
\hline $3 d^{5}{ }^{4} D 4 d$ & $f^{3} G^{e}$ & 0.53051 & 0.526 & $3 d^{5}{ }^{4} D 5 s$ & $f^{3} D^{e}$ & 0.52381 & 0.507 \\
\hline $3 d^{5} c^{2} D 4 p$ & $q^{3} F^{o}$ & $0.50945 \mathrm{Ek}$ & 0.433 & $3 d^{5} c^{2} D 4 p$ & $r^{3} D^{o}$ & $0.49426 \mathrm{Ek}$ & 0.420 \\
\hline $3 d^{52} I 5 s$ & $c^{3} I^{e}$ & 0.45865 & 0.446 & $3 d^{54} G 5 p$ & $p^{3} F^{o}$ & 0.43399 & 0.423 \\
\hline $3 d^{5}{ }^{4} G 5 p$ & $u^{3} H^{o}$ & 0.43338 & 0.422 & $3 d^{5}{ }^{4} G 5 p$ & $s^{3} G^{o}$ & 0.42559 & 0.412 \\
\hline $3 d^{5}{ }^{4} D 5 p$ & $q^{3} D^{o}$ & 0.37360 & 0.362 & $3 d^{5}{ }^{4} D 5 p$ & $o^{3} F^{o}$ & 0.37290 & 0.358 \\
\hline $3 d^{52} I 5 p$ & $x^{3} I^{o}$ & 0.30724 & 0.294 & $3 d^{52} I 5 p$ & $t^{3} H^{o}$ & 0.30266 & 0.289 \\
\hline $3 d^{5{ }^{4}} G 6 s$ & $g^{3} G^{e}$ & 0.21115 & 0.207 & $3 d^{5}{ }^{4} D 6 s$ & $g^{3} D^{e}$ & 0.15486 & 0.147 \\
\hline $3 d^{6}$ & $a^{1} I^{e}$ & 1.97620 & 1.815 & $3 d^{6}$ & $a^{1} G^{e} 2$ & 1.97137 & 1.836 \\
\hline $3 d^{6}$ & $a^{1} S^{e} 2$ & 1.93560 & 1.820 & $3 d^{6}$ & $a^{1} D^{e} 2$ & 1.92656 & 1.793 \\
\hline $3 d^{6}$ & $a^{1} F^{e}$ & 1.86192 & 1.717 & $3 d^{6}$ & $b^{1} G^{e} 1$ & 1.73139 & 1.581 \\
\hline $3 d^{6}$ & $b^{1} D^{e}$ & $1.55075 \mathrm{Ek}$ & 1.376 & $3 d^{52} I 4 s$ & $b^{1} I^{e}$ & 1.49256 & 1.365 \\
\hline $3 d^{5}{ }^{2} D_{3} 4 s$ & $c^{1} D^{e}$ & 1.46142 & 1.400 & $3 d^{5}{ }^{2} F_{2} 4 s$ & $b^{1} F^{e}$ & 1.45181 & 1.360 \\
\hline $3 d^{52} H 4 s$ & $a^{1} H^{e}$ & 1.40969 & 1.298 & $3 d^{52} G_{2} 4 s$ & $c^{1} G^{e}$ & 1.40068 & 1.288 \\
\hline $3 d^{5}{ }^{2} F_{1} 4 s$ & $c^{1} F^{e}$ & 1.36852 & 1.258 & $3 d^{6}$ & $b^{1} S^{e}$ & & 1.221 \\
\hline $3 d^{52} S 4 s$ & $c^{1} S^{e}$ & $1.31960 \mathrm{Ek}$ & 1.201 & $3 d^{52} D_{2} 4 s$ & $d^{1} D^{e}$ & 1.25435 & 1.151 \\
\hline $3 d^{5} a^{2} D 4 p$ & $z^{1} F^{o}$ & 1.24115 & 0.976 & $3 d^{5} a^{2} D 4 p$ & $z^{1} D^{o}$ & 1.19781 & 1.007 \\
\hline $3 d^{5}{ }^{2} G_{1} 4 s$ & $d^{1} G^{e}$ & 1.17799 & 1.053 & $3 d^{5}{ }^{2} I 4 p$ & $z^{1} H^{o}$ & 1.05259 & 0.983 \\
\hline $3 d^{5}{ }^{2} I 4 p$ & $z^{1} K^{o}$ & 1.05003 & 0.982 & $3 d^{5} a^{2} F 4 p$ & $z^{1} G^{o}$ & 1.02845 & 0.979 \\
\hline $3 d^{52} P 4 s$ & $a^{1} P^{e}$ & $1.02769 \mathrm{Ek}$ & 0.907 & $3 d^{52} I 4 p$ & $z^{1} I^{o}$ & 1.01588 & 0.942 \\
\hline $3 d^{5} a^{2} D 4 p$ & $z^{1} P^{o}$ & 0.98898 & 0.947 & $3 d^{5} a^{2} F 4 p$ & $y^{1} D^{o}$ & 0.97920 & 0.931 \\
\hline $3 d^{5} a^{2} G 4 p$ & $y^{1} G^{o}$ & 0.97863 & 0.917 & $3 d^{5} a^{2} F 4 p$ & $y^{1} F^{o}$ & 0.97293 & 0.924 \\
\hline $3 d^{52} H 4 p$ & $y^{1} I^{o}$ & 0.96303 & 0.908 & $3 d^{52} D 4 s$ & $e^{1} D^{e}$ & $0.95464 \mathrm{Ek}$ & 0.836 \\
\hline $3 d^{5} a^{2} G 4 p$ & $y^{1} H^{o}$ & 0.93526 & 0.874 & $3 d^{52} H 4 p$ & $x^{1} H^{o}$ & 0.93292 & 0.862 \\
\hline $3 d^{5} a^{2} G 4 p$ & $x^{1} F^{o}$ & 0.93114 & 0.858 & $3 d^{5} b^{2} F 4 p$ & $x^{1} D^{o}$ & 0.92586 & 0.857 \\
\hline $3 d^{5} b^{2} F 4 p$ & $x^{1} G^{o}$ & 0.89492 & 0.825 & $3 d^{5} b^{2} F 4 p$ & $w^{1} F^{o}$ & 0.87996 & 0.800 \\
\hline $3 d^{5}{ }^{2} S 4 p$ & $y^{1} P^{o}$ & 0.87101 & 0.796 & $3 d^{5} b^{2} D 4 p$ & $v^{1} F^{o}$ & 0.79942 & 0.735 \\
\hline $3 d^{5} b^{2} D 4 p$ & $x^{1} P^{o}$ & $0.78552 \mathrm{Ek}$ & 0.718 & $3 d^{5} b^{2} D 4 p$ & $w^{1} D^{o}$ & 0.77580 & 0.710 \\
\hline $3 d^{5} b^{2} G 4 p$ & $w^{1} H^{o}$ & 0.71479 & 0.637 & $3 d^{5} b^{2} G 4 p$ & $w^{1} G^{o}$ & 0.71026 & 0.630 \\
\hline $3 d^{5} b^{2} G 4 p$ & $u^{1} F^{o}$ & 0.70085 & 0.618 & $3 d^{52} P 4 p$ & $v^{1} D^{o}$ & 0.57862 & 0.499 \\
\hline $3 d^{5} c^{2} D 4 p$ & $u^{1} D^{o}$ & 0.48902 & 0.404 & $3 d^{5} c^{2} D 4 p$ & $t^{1} F^{o}$ & 0.47730 & 0.398 \\
\hline
\end{tabular}

higher configurations $3 \mathrm{~d}^{4} 4 \mathrm{~s}$ and $3 \mathrm{~d}^{4} 4 \mathrm{p}$ resulting in missing resonances, and precludes a number of bound states of Fe III and corresponding transition probabilities. The present work entails a more extensive ab initio R-matrix calculation with a 49-state eigenfunction expansion including states dominated by the excited configurations of Fe IV. Following an algebraic transformation of the LS multiplet line strengths to yield fine structure components, the atomic parameters for the dipole allowed transitions, oscillator strengths ( $f$-values), line strengths $(S)$, and the Einstein's $A$-coefficients ( $A$-values), are obtained for a large number of fine structure transitions in Fe III. The method, applied to several other ions including $\mathrm{Fe}$ II (Nahar 1993, 1995; Nahar 1996 N2), is outlined in the next section.

Owing to the difficulty of calculating the forbidden transition probabilities there has been only one previous calculation of the E2 and M1 forbidden transition probabilities of Fe III (Garstang 1957) nearly four decades ago. The difficulty arises from the necessity of including both the relativistic and the electron correlation effects accurately so as to obtain the very small $A$-coefficients with sufficient precision. Recent spectral observations of the forbidden lines of Fe III from sources such as the Orion nebula (Osterbrock et al. 1992), the planetary nebula IC 4997 (Keenan et al. 1993), and the Galactic Center (Chen \& Werner, private communication), have revealed some discrepancies between the observed line ratios and those calculated from the $A$-coefficients calculated by Garstang. In an effort to improve the accuracy of the Fe III transition probabilities, we describe new calculations in the Breit-Pauli approximation with configuration interaction type wavefunctions using the SUPERSTRUCTURE program (Eissner et al. 1974).

\section{Theoretical computations and results}

The calculations for the dipole allowed transitions and the forbidden transitions were carried out independently using different methods. The E1 data was basically calculated 
in the close coupling approximation which represents the correlation effects accurately (as in the Opacity Project work). However, no allowance is made for the relativistic effects in the dipole transitions and fine structure is introduced through an algebraic transformation. The forbidden E2 and M1 transitions however are treated with an atomic structure calculation including both the relativistic and correlation effects as extensively as possible. The following two subsections describe the two sets of calculations.

Table 2. Lifetimes, $\tau$ (ns), of Fe III

\begin{tabular}{llrr}
\hline state & & $\begin{array}{r}\text { lifetime } \\
\text { Expt }^{\mathrm{a}}\end{array}$ & BKP \\
\hline$z^{5} H^{o}$ & 1.9 & $1.6(0.3)$ & 1.7 \\
$z^{5} G^{o}$ & 2.1 & $2.1(0.3)$ & 2.0 \\
$z^{3} H^{o}$ & 1.4 & $1.7(0.2)$ & 1.4 \\
$y^{1} I^{o}$ & 0.82 & $1.2(0.2)$ & 1.2 \\
\hline
\end{tabular}

a Andersen et al. (1977)

\subsection{Dipole allowed fine structure transitions}

Some details of the method for obtaining the atomic quantities for the fine structure transitions are given in Nahar (1995, 1996 N2). The non-relativistic 49-state CC eigenfunction expansion for Fe IV is obtained from the atomic structure code SUPERSTRUCTURE (Eissner et al. 1974; Nussbaumer \& Storey 1978) including the LS terms from the ground configuration $3 \mathrm{~d}^{5}$ and excited configurations $3 \mathrm{~d}^{4} 4 \mathrm{~s}$ and $3 \mathrm{~d}^{4} 4 \mathrm{p}$ of Fe IV (discussed in detail by Nahar 1996, N1). The computations for the radiative data of LS dipole line strengths of Fe III are carried out using the R-matrix codes of the OP extended for the Iron Project (Hummer et al. 1993). A major task in the calculations is the spectral identification of the large number of computed bound states. The calculated states of Fe III are identified through a detailed analysis of the quantum defects and the fractional contribution of the wavefunction in the dominant bound "channel". This refers to the terminology of electron-atom collision theory; for the bound states all available channels are 'closed'. A computer code, ELEVID (Nahar 1995), is employed for this purpose.

The total number of computed LS bound states of Fe III that lie below the first ionization threshold is 805 , compared to 199 observed ones (Sugar \& Corliss 1985; Ekberg 1993). The number of corresponding dipole allowed LS multiplets is 11979 . Table 1 presents a comparison of the calculated LS term energies with the observed ones. The observed LS energies are the statistical average of the observed fine structure levels. An asterisk next to an LS term in the table indicates an incomplete set of observed fine structure levels for that term. Most of the calculated energies are within $7 \%$ of the measured values (N1); the largest difference is $21.4 \%$ with the measured energy of the $3 \mathrm{~d}^{5}\left(\mathrm{a}^{2} \mathrm{D}\right) 4 \mathrm{p}\left(\mathrm{z}^{1} \mathrm{~F}^{\circ}\right)$ state which corresponds to high percentage of admixtures with other states (Sugar \& Corliss 1985). One purpose of presenting the energy table here is to provide the degeneracy assignments for states of the same LS symmetry. For convenience, the assignment made differs somewhat from the assignments in the table of observed levels by Sugar \& Corliss (1985). An ascending order of alphabet is assigned for the even parity states of a given symmetry, and a descending order for the odd parity states. The table also presents one calculated state, $3 \mathrm{~d}^{6}\left(\mathrm{~b}^{1} \mathrm{~S}^{\mathrm{e}}\right)$, which has not been observed yet; we include it for the fine structure transitions in the present work.

The $f$-, $S$, and $A$-values for the dipole allowed fine structure transitions are obtained through algebraic transformations of the LS multiplet line strengths using the spectroscopiclly observed energies. For the cases where the observed energies are not found for all the fine structure components of a LS term, the splitting is carried out through the LS $f$-value as described in Nahar (1995, 1996 N2). Computations are carried out using the code JJTOLS (Nahar 1995).

The radiative transitions of Fe III have not been studied much experimentally. The available values correspond to lifetime measurements of a few LS terms of Fe III, $\mathrm{z}^{5} \mathrm{H}^{\circ}, \mathrm{z}^{5} \mathrm{G}^{\circ}, \mathrm{z}^{3} \mathrm{H}^{\circ}$, and $\mathrm{y}^{1} \mathrm{I}^{\circ}$, by Andersen et al. (1977). Comparison of the calculated lifetimes using the present LS $A$-values is made in Table 2 (taken from Nahar 1996, N1) with these measured values. The BKP values in the table correspond to the calculated lifetimes of Andersen et al. where they used the $f$-values calculated by $\mathrm{Ku}$ rucz \& Peytremann (1975) and Biemont (1976). While the present calculated values agree with the two quintets within experimental uncertainty, the lifetime of the triplet state agrees with the other calculated value (Andersen et al. 1977) rather than the observed value, and the lifetime for the singlet state comes out lower than the measured or the other calculated value. The reason for the present lower value could be because of the relatively high angular momentum of the state $(L=6)$ for which it is often difficult to i) include sufficient correlation from other states, and ii) employ a sufficiently large R-matrix boundary to represent the bound state wavefunction in the inner region for the high-L states.

Some comparison is made of the present $f$ - and $A$ values with other calculated values in Table 3 . Kurucz \& Peytremann (1975), Biemont (1976), Fawcett (1989), and Ekberg (1993) have calculated the $f$ - and $A$-values for a large number of fine structure transitions in $\mathrm{Fe}$ III. All of them have used various versions of Cowan's atomic structure code where semiempirical optimization is carried out. The values of Kurucz \& Pytremann (1975) are the same as those obtained by Biemont (1976). Present $f$-values have better agreement with Kurucz and Peytremann than with the others in general. Fawcett's 
values are somewhat higher than the present values except for transition $\mathrm{a}^{3} \mathrm{D}^{\mathrm{e}} \rightarrow \mathrm{u}^{3} \mathrm{P}^{\circ}$ where agreement is good. It is difficult to judge Ekberg's calculated $A$-values since they differ from the present values although for some transitions the agreement is fair to good. Even though these semiempirical calculations are similar to each other, their different optimizations can yield results differing from each other. Comparison is also made with the LS $f$-values of Sawey \& Berrington (1992). Except for the transition $\mathrm{a}^{3} \mathrm{P}^{\mathrm{e}} \rightarrow \mathrm{y}^{3} \mathrm{~S}^{\circ}$, their values differ quite a bit from the present values, from about $14 \%$ to about $35 \%$.

A sample set of $f_{-}, S$-, and $A$-values for the dipole allowed fine structure transitions in Fe III is presented in Table 4 while the complete table is available electronically. The format for the transitional values is the same for both the sample and the complete tables. The first line of each subset of data corresponds to the LS transition followed by the fine structure components. The degeneracy of the transitional states in the table correspond to those assigned in Table 1 for the term energies. The energies of the initial and final levels in the fine structure set are given in unit of $\mathrm{cm}^{-1}$ while the initial and the final LS states and the transitional energy differences are given in Rydberg unit. The $A$-values are given in $\mathrm{s}^{-1}$. An asterisk $\left(^{*}\right)$ below a LS state indicates incomplete set of observed energy levels for the state and an asterisk for the transitional energy indicates that one or both the transitional levels are missing from the observed energy set. There are 9797 fine structure transitions corresponding to 1408 ones in LS coupling in the complete table.

The results obtained correspond to 200 bound states of Fe III (where 199 are observed ones) while the total number of calculated bound states is 805 . Hence, this report presents only a small fraction of the calculated radiative data that have been processed for the fine structure transitions.

Based on accuracy of the calculated energies and comparison with other work, the accuracy for most of the present, except the weak ones, $f$-, $S$, and $A$-values should be accurate within $20 \%$. Because of low charge of the ion, the relativistic effects on the results are expected to be small.

\subsection{Forbidden electric quadrupole (E2) and magnetic dipole (M1) transitions}

The atomic parameters for the forbidden electric quadrupole and magnetic dipole transitions in Fe III are obtained from atomic structure calculations employing a new version of SUPERSTRUCTURE that incorporates the optimisation of individual orbitals $n \ell$ (W. Eissner, private communication). Table 5 presents the calculated and the experimental fine structure energy levels of the 34 fine structure levels of the 16 LS terms dominated by the ground configuration $3 \mathrm{~d}^{6}$, together with the list of configurations in the configuration-interaction
(CI) expansion, and the scaling parameters for the scaled Thomas-Fermi-Dirac-Amaldi type potential used in SUPERSTRUCTURE. As the Breit-Pauli structure calculations can be extremely CPU intensive with large CI expansions, a considerable amount of effort is devoted to optimisation with a number of different configurations. The primary criteria are the level of agreement with observed values for (a) the fine structure splittings within the lowest LS terms, and (b) the LS term energies themselves. Another criterion employed was that the calculated $A$-values should be relatively stable with small changes in scaling parameters.

A comparison with the earlier Breit-Pauli calculations of Zhang \& Pradhan (1995) shows a considerable improvement in the calculated eigenenergies compared with the experimental values for most of the levels. We employ the observed energies in the calculation of the electric quadrupole and the magnetic dipole transition probabilites, $A^{q}$ and $A^{m}$, which are given as:

$$
A_{j, i}^{q}(\mathrm{E} 2)=2.673310^{3}\left(E_{j}-E_{i}\right)^{5} \mathcal{S}^{q}(i, j) \mathrm{s}^{-1},
$$

and

$$
A_{j, i}^{m}(\mathrm{M} 1)=3.564410^{4}\left(E_{j}-E_{i}\right)^{3} \mathcal{S}^{m}(i, j) \mathrm{s}^{-1},
$$

where $E_{j}>E_{i}$ (the energies are in Rydbergs), and $\mathcal{S}$ is the line strength for the corresponding transition.

The computed $A^{q}$ and $A^{m}$ for 362 transitions are given in Table 6, along with the observed wavelengths in microns. The $A^{q}$ in general are much smaller than the $A^{m}$. There are many transitions where one or the other is negligible, usually the $A^{q}$.

Owing to the widespread use of the only other previous calculation by Garstang (1957), it is important to establish the general level of differences with the previous work. Table 7 gives a detailed comparison of the magnetic dipole $A^{m}$, which is the usual dominant radiative decay mode for nearly all transitions, selected to represent all three cases: (a) good agreement, $<10 \%$, (b) significant differences, about $10-30 \%$, and (c) large differences up to an order of magnitude or more. For brevity we forego a more detailed discussion of these differences, but note that most of the transitions fall in the category (b). Some fine structure components of the multiplets $a^{3} G-a^{5} D, a^{3} G-a^{3} H$, $a^{1} D-a^{3} D, a^{3} D-a^{3} P$ show the largest differences.

In order to further investigate the effect of these differences between the results of Garstang, hitherto employed in all calculations of Fe III spectra, and the present ones, we constructed a Non-LTE collisional-radiative model (Bautista \& Pradhan 1995) using the new collisional excitation rate coefficients (Zhang \& Pradhan 1995, and the following paper) and the two sets of $A$-values. A number of Fe III line ratios were computed for all available 
Table 3. Comparison of the present $f$ - and $A$-values with other calculations

\begin{tabular}{|c|c|c|c|c|c|c|}
\hline \multirow[t]{2}{*}{ Transition } & \multirow[t]{2}{*}{$g_{i}$} & \multirow[t]{2}{*}{$g_{f}$} & \multirow[b]{2}{*}{ Present } & \multirow{2}{*}{$\begin{array}{c}f_{i f} \\
\text { Others }\end{array}$} & \multicolumn{2}{|c|}{$A_{f i}\left(\mathrm{~s}^{-1}\right)$} \\
\hline & & & & & Present & Others \\
\hline \multirow[t]{4}{*}{$a^{7} S^{e} \rightarrow z^{7} P^{o}$} & 7 & 21 & 0.86 & $0.994^{d}$ & & \\
\hline & 7 & 9 & 0.37 & & $5.36(8)$ & \\
\hline & 7 & 7 & 0.29 & $0.35^{b}$ & $5.21(8)$ & $6.59(8)^{c}$ \\
\hline & 7 & 5 & 0.203 & $0.25^{b}$ & $5.11(8)$ & $4.63(8)^{c}$ \\
\hline \multirow[t]{14}{*}{$a^{5} G^{e} \rightarrow z^{5} G^{o}$} & 45 & 45 & 0.28 & $0.32^{d}$ & & \\
\hline & 13 & 13 & 0.26 & $0.29^{a}, 0.33^{b}$ & $4.40(8)$ & $5.85(8)^{c}$ \\
\hline & 13 & 11 & 0.019 & $0.031^{b}$ & $3.70(7)$ & $2.32(7)^{c}$ \\
\hline & 11 & 13 & 0.022 & $0.0011^{b}$ & $3.13(7)$ & $3.13(7)^{c}$ \\
\hline & 11 & 11 & 0.225 & $0.25^{a}, 0.29^{b}$ & $3.78(8)$ & $5.30(8)^{c}$ \\
\hline & 11 & 9 & 0.032 & $0.050^{b}$ & $6.58(7)$ & $9.36(7)^{c}$ \\
\hline & 9 & 11 & 0.039 & $0.0044^{b}$ & $5.39(7)$ & $1.98(7)^{c}$ \\
\hline & 9 & 9 & 0.20 & $0.21^{a}, 0.26^{b}$ & $3.36(8)$ & $4.64(8)^{c}$ \\
\hline & 9 & 7 & 0.038 & $0.048^{a}, 0.056^{b}$ & $8.28(7)$ & $1.04(8)^{c}$ \\
\hline & 7 & 9 & 0.049 & $0.01^{b}$ & $6.45(7)$ & $2.78(6)^{c}$ \\
\hline & 7 & 7 & 0.20 & $0.22^{a}, 0.25^{b}$ & $3.29(8)$ & $4.40(8)^{c}$ \\
\hline & 7 & 5 & 0.033 & $0.044^{b}$ & $7.75(7)$ & $8.24(7)^{c}$ \\
\hline & 5 & 7 & 0.046 & $0.041^{a}, 0.015^{b}$ & $5.54(7)$ & \\
\hline & 5 & 5 & 0.23 & $0.25^{a}, 0.27^{b}$ & $3.88(7)$ & $4.58(8)^{c}$ \\
\hline \multirow[t]{13}{*}{$b^{5} D^{e} \rightarrow y^{5} F^{o}$} & 25 & 35 & 0.35 & $0.26^{d}$ & & \\
\hline & 9 & 11 & 0.31 & $0.36^{a}, 0.39^{b}$ & $4.50(8)$ & $7.30(8)^{c}$ \\
\hline & 9 & 9 & 0.042 & $0.027^{b}$ & $7.40(7)$ & $7.12(7)^{c}$ \\
\hline & 9 & 7 & 0.0028 & & $6.26(6)$ & $1.01(6)^{c}$ \\
\hline & 7 & 9 & 0.27 & $0.27^{a}, 0.37^{b}$ & $3.67(8)$ & $6.49(8)^{c}$ \\
\hline & 7 & 7 & 0.075 & $0.074^{a}, 0.065^{b}$ & $1.30(8)$ & \\
\hline & 7 & 5 & 0.0071 & $0.0033^{b}$ & $1.72(7)$ & \\
\hline & 5 & 7 & 0.24 & $0.28^{a}, 0.34^{b}$ & $2.98(8)$ & $5.98(8)^{c}$ \\
\hline & 5 & 5 & 0.099 & $0.10^{a}, 0.11^{b}$ & $1.72(8)$ & $1.96(8)^{c}$ \\
\hline & 5 & 3 & 0.099 & $0.0099^{a}, 0.011^{b}$ & $2.84(7)$ & $1.67(7)^{c}$ \\
\hline & 3 & 5 & 0.23 & $0.27^{a}, 0.32^{b}$ & $2.41(8)$ & $5.63(8)^{c}$ \\
\hline & 3 & 3 & 0.12 & $0.13^{a}, 0.13^{b}$ & $2.00(8)$ & $3.64(8)^{c}$ \\
\hline & 1 & 3 & 0.35 & $0.39^{a}, 0.425^{b}$ & $2.00(8)$ & $7.98(8)^{c}$ \\
\hline \multirow[t]{4}{*}{$a^{3} P^{e} \rightarrow y^{3} S^{o}$} & 9 & 3 & 0.0031 & $0.0034^{d}$ & & \\
\hline & 5 & 3 & 0.0032 & $0.045^{b}$ & $9.63(7)$ & \\
\hline & 3 & 3 & 0.0031 & & $5.64(7)$ & \\
\hline & 1 & 3 & 0.0031 & & $1.86(7)$ & $4.6(7)^{c}$ \\
\hline \multirow[t]{7}{*}{$a^{3} D^{e} \rightarrow u^{3} P^{o}$} & 15 & 9 & 0.011 & $0.0093^{d}$ & & \\
\hline & 7 & 5 & 0.011 & $0.010^{b}$ & $2.31(8)$ & $1.53(8)^{c}$ \\
\hline & 5 & 5 & 0.0028 & $0.003^{b}$ & $4.15(7)$ & \\
\hline & 3 & 5 & 0.00031 & & $2.76(6)$ & \\
\hline & 5 & 3 & 0.0084 & $0.013^{b}$ & $2.06(8)$ & $1.19(8)^{c}$ \\
\hline & 3 & 3 & 0.0047 & $0.005^{b}$ & $6.85(7)$ & \\
\hline & 3 & 1 & 0.0062 & $0.0063^{b}$ & $2.73(8)$ & \\
\hline \multirow[t]{7}{*}{${ }^{b} 3^{D} e \rightarrow y^{3} F^{o}$} & 15 & 21 & 0.37 & $0.43^{d}$ & & \\
\hline & 7 & 9 & 0.34 & $0.36^{a}, 0.39^{b}$ & $4.11(8)$ & $6.19(8)^{c}$ \\
\hline & 7 & 7 & 0.029 & $0.028^{a}, 0.014^{b}$ & $4.64(7)$ & $2.87(7)^{c}$ \\
\hline & 7 & 5 & 0.00083 & & $1.84(6)$ & $2.47(6)^{c}$ \\
\hline & 5 & 7 & 0.33 & $0.35^{a}, 0.40^{b}$ & $3.67(8)$ & $6.24(8)^{c}$ \\
\hline & 5 & 5 & 0.041 & $0.048^{a}, 0.044^{b}$ & $6.45(7)$ & $9.00(7)^{c}$ \\
\hline & 3 & 5 & 0.37 & $0.39^{a}, 44^{b}$ & $3.48(8)$ & $6.70(8)^{c}$ \\
\hline$d^{1} D^{e} \rightarrow w^{1} D^{o}$ & 5 & 5 & 0.27 & $0.31^{a}, 0.31^{d}$ & $4.98(8)$ & $6.16(8)^{c}$ \\
\hline$d^{1} D^{e} \rightarrow v^{1} F^{o}$ & 5 & 7 & 0.35 & $0.36^{a}, 0.40^{d}$ & $4.15(8)$ & $6.58(8)^{c}$ \\
\hline$b^{1} I^{e} \rightarrow z^{1} K^{o}$ & 13 & 15 & 0.33 & $0.33^{\mathrm{a}}, 0.54^{\mathrm{b}}, 0.37^{\mathrm{d}}$ & $4.53(8)$ & $6.01(8)^{\mathrm{c}}$ \\
\hline
\end{tabular}

a) Kurucz \& Peytremann (1975), b) Fawcett (1989). c) Ekberg(1993). d) Sawey \& Berrington (1993). 
Table 4. Sample table for the $f$-, $S$, and $A$-values for transitions in Fe III

\begin{tabular}{|c|c|c|c|c|c|c|c|c|}
\hline Transition & $\begin{array}{c}E_{i} \\
\mathrm{~cm}^{-1}\end{array}$ & $\begin{array}{c}E_{f} \\
\mathrm{~cm}^{-1}\end{array}$ & $\begin{array}{l}E_{f i} \\
\text { Ry }\end{array}$ & $g_{i}$ & $g_{f}$ & $f_{i f}$ & $S$ & $\begin{array}{l}A_{f i} \\
\mathrm{~s}^{-1}\end{array}$ \\
\hline \multirow[t]{4}{*}{$a^{7} S^{e} \rightarrow z^{7} P^{o}$} & 1.9786 & 1.5013 & $4.774 \mathrm{E}-01$ & 7 & 21 & $8.606 \mathrm{E}-01$ & $3.786 \mathrm{E}+01$ & $5.251 \mathrm{E}+08$ \\
\hline & 30088.840 & 82846.590 & $4.808 \mathrm{E}-01$ & 7 & 9 & $3.714 \mathrm{E}-01$ & $1.622 \mathrm{E}+01$ & $5.363 \mathrm{E}+08$ \\
\hline & 30088.840 & 82333.920 & $4.761 \mathrm{E}-01$ & 7 & 7 & $2.861 \mathrm{E}-01$ & $1.262 \mathrm{E}+01$ & $5.209 \mathrm{E}+08$ \\
\hline & 30088.840 & 82001.730 & $4.731 \mathrm{E}-01$ & 7 & 5 & $2.030 \mathrm{E}-01$ & $9.014 \mathrm{E}+00$ & $5.110 \mathrm{E}+08$ \\
\hline \multirow[t]{10}{*}{$a^{5} D^{e} \rightarrow z^{5} P^{o}$} & 2.2490 & 1.4395 & $8.094 \mathrm{E}-01$ & 25 & 15 & $7.706 \mathrm{E}-02$ & $7.140 \mathrm{E}+00$ & $6.759 \mathrm{E}+08$ \\
\hline & 0.000 & 89084.790 & $8.118 \mathrm{E}-01$ & 9 & 7 & $7.728 \mathrm{E}-02$ & $2.570 \mathrm{E}+00$ & $5.259 \mathrm{E}+08$ \\
\hline & 436.200 & 89084.790 & $8.078 \mathrm{E}-01$ & 7 & 7 & $2.563 \mathrm{E}-02$ & $6.664 \mathrm{E}-01$ & $1.344 \mathrm{E}+08$ \\
\hline & 738.900 & 89084.790 & $8.051 \mathrm{E}-01$ & 5 & 7 & $5.109 \mathrm{E}-03$ & $9.519 \mathrm{E}-02$ & $1.900 \mathrm{E}+07$ \\
\hline & 436.200 & 89334.510 & $8.101 \mathrm{E}-01$ & 7 & 5 & $5.141 \mathrm{E}-02$ & $1.333 \mathrm{E}+00$ & $3.794 \mathrm{E}+08$ \\
\hline & 738.900 & 89334.510 & $8.073 \mathrm{E}-01$ & 5 & 5 & $4.483 \mathrm{E}-02$ & $8.330 \mathrm{E}-01$ & $2.347 \mathrm{E}+08$ \\
\hline & 932.400 & 89334.510 & $8.056 \mathrm{E}-01$ & 3 & 5 & $1.917 \mathrm{E}-02$ & $2.142 \mathrm{E}-01$ & $5.996 \mathrm{E}+07$ \\
\hline & 738.900 & 89491.390 & $8.088 \mathrm{E}-01$ & 5 & 3 & $2.695 \mathrm{E}-02$ & $4.998 \mathrm{E}-01$ & $2.360 \mathrm{E}+08$ \\
\hline & 932.400 & 89491.390 & $8.070 \mathrm{E}-01$ & 3 & 3 & $5.762 \mathrm{E}-02$ & $6.426 \mathrm{E}-01$ & $3.014 \mathrm{E}+08$ \\
\hline & 1027.300 & 89491.390 & $8.061 \mathrm{E}-01$ & 1 & 3 & 7.674E-02 & $2.856 \mathrm{E}-01$ & $1.335 \mathrm{E}+08$ \\
\hline \multirow[t]{13}{*}{$a^{5} D^{e} \rightarrow z^{5} D^{o}$} & 2.2490 & 1.1867 & $1.062 \mathrm{E}+00$ & 25 & 25 & $9.603 \mathrm{E}-06$ & $6.780 \mathrm{E}-04$ & $8.704 \mathrm{E}+04$ \\
\hline & 0.000 & 117521.910 & $1.071 \mathrm{E}+00$ & 9 & 9 & $8.068 \mathrm{E}-06$ & $2.034 \mathrm{E}-04$ & $7.432 \mathrm{E}+04$ \\
\hline & 0.000 & 117068.560 & $1.067 \mathrm{E}+00$ & 9 & 7 & $1.607 \mathrm{E}-06$ & $4.068 \mathrm{E}-05$ & $1.889 \mathrm{E}+04$ \\
\hline & 436.200 & 117521.910 & $1.067 \mathrm{E}+00$ & 7 & 9 & $2.067 \mathrm{E}-06$ & $4.068 \mathrm{E}-05$ & $1.470 \mathrm{E}+04$ \\
\hline & 436.200 & 117068.560 & $1.063 \mathrm{E}+00$ & 7 & 7 & $4.804 \mathrm{E}-06$ & $9.492 \mathrm{E}-05$ & $4.359 \mathrm{E}+04$ \\
\hline & 436.200 & 116419.390 & $1.057 \mathrm{E}+00$ & 7 & 5 & $2.730 \mathrm{E}-06$ & $5.424 \mathrm{E}-05$ & $3.429 \mathrm{E}+04$ \\
\hline & 738.900 & 117068.560 & $1.060 \mathrm{E}+00$ & 5 & 7 & $3.833 \mathrm{E}-06$ & $5.424 \mathrm{E}-05$ & $2.471 \mathrm{E}+04$ \\
\hline & 738.900 & 116419.390 & $1.054 \mathrm{E}+00$ & 5 & 5 & $2.383 \mathrm{E}-06$ & $3.390 \mathrm{E}-05$ & $2.127 \mathrm{E}+04$ \\
\hline & 738.900 & 116380.070 & $1.054 \mathrm{E}+00$ & 5 & 3 & $3.334 \mathrm{E}-06$ & $4.746 \mathrm{E}-05$ & $4.957 \mathrm{E}+04$ \\
\hline & 932.400 & 116419.390 & $1.052 \mathrm{E}+00$ & 3 & 5 & $5.550 \mathrm{E}-06$ & $4.746 \mathrm{E}-05$ & $2.962 \mathrm{E}+04$ \\
\hline & 932.400 & 116380.070 & $1.052 \mathrm{E}+00$ & 3 & 3 & $7.925 \mathrm{E}-07$ & $6.780 \mathrm{E}-06$ & $7.045 \mathrm{E}+03$ \\
\hline & 932.400 & 116364.760 & $1.052 \mathrm{E}+00$ & 3 & 1 & $3.170 \mathrm{E}-06$ & $2.712 \mathrm{E}-05$ & $8.452 \mathrm{E}+04$ \\
\hline & 1027.300 & 116380.070 & $1.051 \mathrm{E}+00$ & 1 & 3 & $9.503 \mathrm{E}-06$ & $2.712 \mathrm{E}-05$ & $2.811 \mathrm{E}+04$ \\
\hline \multirow{13}{*}{$\begin{array}{r}a^{5} D^{e} \rightarrow y^{5} D^{o} \\
*\end{array}$} & 2.2490 & 1.1332 & $1.116 \mathrm{E}+00$ & 25 & 25 & $8.347 \mathrm{E}-02$ & $5.611 \mathrm{E}+00$ & $8.348 \mathrm{E}+08$ \\
\hline & & * & & 9 & 9 & $6.956 \mathrm{E}-02$ & $1.683 \mathrm{E}+00$ & $6.956 \mathrm{E}+08$ \\
\hline & & * & & 9 & 7 & $1.391 \mathrm{E}-02$ & $3.366 \mathrm{E}-01$ & $1.789 \mathrm{E}+08$ \\
\hline & 436.200 & 122944.000 & $1.116 \mathrm{E}+00$ & 7 & 9 & $1.790 \mathrm{E}-02$ & $3.366 \mathrm{E}-01$ & $1.393 \mathrm{E}+08$ \\
\hline & & * & & 7 & 7 & $4.174 \mathrm{E}-02$ & $7.855 \mathrm{E}-01$ & $4.174 \mathrm{E}+08$ \\
\hline & 436.200 & 122628.200 & $1.114 \mathrm{E}+00$ & 7 & 5 & $2.380 \mathrm{E}-02$ & $4.489 \mathrm{E}-01$ & $3.319 \mathrm{E}+08$ \\
\hline & & * & & 5 & 7 & $3.339 \mathrm{E}-02$ & $4.489 \mathrm{E}-01$ & $2.385 \mathrm{E}+08$ \\
\hline & 738.900 & 122628.200 & $1.111 \mathrm{E}+00$ & 5 & 5 & $2.077 \mathrm{E}-02$ & $2.805 \mathrm{E}-01$ & $2.059 \mathrm{E}+08$ \\
\hline & 738.900 & 122843.000 & $1.113 \mathrm{E}+00$ & 5 & 3 & $2.913 \mathrm{E}-02$ & $3.928 \mathrm{E}-01$ & $4.828 \mathrm{E}+08$ \\
\hline & 932.400 & 122628.200 & $1.109 \mathrm{E}+00$ & 3 & 5 & $4.840 \mathrm{E}-02$ & $3.928 \mathrm{E}-01$ & $2.869 \mathrm{E}+08$ \\
\hline & 932.400 & 122843.000 & $1.111 \mathrm{E}+00$ & 3 & 3 & $6.926 \mathrm{E}-03$ & $5.611 \mathrm{E}-02$ & $6.865 \mathrm{E}+07$ \\
\hline & & * & & 3 & 1 & $2.782 \mathrm{E}-02$ & $2.244 \mathrm{E}-01$ & $8.348 \mathrm{E}+08$ \\
\hline & 1027.300 & 122843.000 & $1.110 \mathrm{E}+00$ & 1 & 3 & $8.304 \mathrm{E}-02$ & $2.244 \mathrm{E}-01$ & $2.740 \mathrm{E}+08$ \\
\hline \multirow[t]{13}{*}{$a^{5} D^{e} \rightarrow z^{5} F^{o}$} & 2.2490 & 1.1909 & $1.058 \mathrm{E}+00$ & 25 & 35 & $1.190 \mathrm{E}-01$ & $8.438 \mathrm{E}+00$ & $7.646 \mathrm{E}+08$ \\
\hline & 0.000 & 116 & 足 & 9 & 11 & 1 & $2.652 \mathrm{E}+00$ & $7.688 \mathrm{E}+08$ \\
\hline & 0.000 & 116467.410 & $61 \mathrm{E}+00$ & 9 & 9 & 1.421 & $3.616 \mathrm{E}-01$ & $1.286 \mathrm{E}+08$ \\
\hline & 0.000 & 116475.440 & $1.061 \mathrm{E}+00$ & 9 & 7 & $9.477 \mathrm{E}-04$ & $2.411 \mathrm{E}-02$ & $1.103 \mathrm{E}+07$ \\
\hline & 436.200 & 116467.410 & $1.057 \mathrm{E}+00$ & 7 & 9 & $9.104 \mathrm{E}-02$ & $1.808 \mathrm{E}+00$ & $6.358 \mathrm{E}+08$ \\
\hline & 436.200 & 116475.440 & $1.057 \mathrm{E}+00$ & 7 & 7 & $2.549 \mathrm{E}-02$ & $5.063 \mathrm{E}-01$ & $2.290 \mathrm{E}+08$ \\
\hline & 436.200 & 116975.050 & $1.062 \mathrm{E}+00$ & 7 & 5 & $2.438 \mathrm{E}-03$ & $4.822 \mathrm{E}-02$ & $3.093 \mathrm{E}+07$ \\
\hline & 738.900 & 116475.440 & $1.055 \mathrm{E}+00$ & 5 & 7 & $8.136 \mathrm{E}-02$ & $1.157 \mathrm{E}+00$ & $5.192 \mathrm{E}+08$ \\
\hline & 738.900 & 116975.050 & $1.059 \mathrm{E}+00$ & 5 & 5 & $3.405 \mathrm{E}-02$ & $4.822 \mathrm{E}-01$ & $3.069 \mathrm{E}+08$ \\
\hline & 738.900 & 116937.570 & $1.059 \mathrm{E}+00$ & 5 & 3 & $3.404 \mathrm{E}-03$ & $4.822 \mathrm{E}-02$ & $5.109 \mathrm{E}+07$ \\
\hline & 932.400 & 116975.050 & $1.058 \mathrm{E}+00$ & 3 & 5 & $7.932 \mathrm{E}-02$ & $6.750 \mathrm{E}-01$ & $4.275 \mathrm{E}+08$ \\
\hline & 932.400 & 116937.570 & $1.057 \mathrm{E}+00$ & 3 & 3 & $3.964 \mathrm{E}-02$ & $3.375 \mathrm{E}-01$ & $3.558 \mathrm{E}+08$ \\
\hline & 1027.300 & 116937.570 & $1.056 \mathrm{E}+00$ & 1 & 3 & $1.188 \mathrm{E}-01$ & $3.375 \mathrm{E}-01$ & $3.550 \mathrm{E}+08$ \\
\hline \multirow[t]{4}{*}{$a^{3} P^{e} \rightarrow z^{3} S^{o}$} & 2.0703 & 1.1011 & $9.692 \mathrm{E}-01$ & 9 & 3 & $5.559 \mathrm{E}-02$ & $1.549 \mathrm{E}+00$ & $1.258 \mathrm{E}+09$ \\
\hline & 00 & 12 & $9.750 \mathrm{E}-01$ & 5 & 3 & $5.592 \mathrm{E}-02$ & 01 & 7.116 \\
\hline & 20688.400 & 126390.570 & $3 \mathrm{E}-01$ & 3 & 3 & $5.525 \mathrm{E}-02$ & $5.162 \mathrm{E}-01$ & $4.118 \mathrm{E}+08$ \\
\hline & 21208.500 & 126390.570 & $9.585 \mathrm{E}-01$ & 1 & 3 & $5.498 \mathrm{E}-02$ & $1.721 \mathrm{E}-01$ & $1.352 \mathrm{E}+08$ \\
\hline
\end{tabular}


Table 4. continued

\begin{tabular}{|c|c|c|c|c|c|c|c|c|}
\hline Transition & $\begin{array}{c}E_{i} \\
\mathrm{~cm}^{-1}\end{array}$ & $\begin{array}{c}E_{f} \\
\mathrm{~cm}^{-1}\end{array}$ & $\begin{array}{c}E_{f i} \\
\text { Ry }\end{array}$ & $g_{i}$ & $g_{f}$ & $f_{i f}$ & $\mathrm{~S}$ & $\begin{array}{l}A_{f i} \\
\mathrm{~s}^{-1}\end{array}$ \\
\hline \multirow[t]{7}{*}{$a^{3} P^{e} \rightarrow z^{3} P^{o}$} & 2.0703 & 1.1607 & $9.096 \mathrm{E}-01$ & 9 & 9 & $6.004 \mathrm{E}-02$ & $1.782 \mathrm{E}+00$ & $3.989 \mathrm{E}+08$ \\
\hline & 19404.800 & 119697.640 & $9.140 \mathrm{E}-01$ & 5 & 5 & $4.525 \mathrm{E}-02$ & $7.426 \mathrm{E}-01$ & $3.036 \mathrm{E}+08$ \\
\hline & 19404.800 & 119982.260 & $9.166 \mathrm{E}-01$ & 5 & 3 & $1.512 \mathrm{E}-02$ & $2.475 \mathrm{E}-01$ & $1.701 \mathrm{E}+08$ \\
\hline & 20688.400 & 119697.640 & $9.023 \mathrm{E}-01$ & 3 & 5 & $2.481 \mathrm{E}-02$ & $2.475 \mathrm{E}-01$ & $9.736 \mathrm{E}+07$ \\
\hline & 20688.400 & 119982.260 & $9.049 \mathrm{E}-01$ & 3 & 3 & $1.493 \mathrm{E}-02$ & $1.485 \mathrm{E}-01$ & $9.820 \mathrm{E}+07$ \\
\hline & 20688.400 & 120179.950 & $9.067 \mathrm{E}-01$ & 3 & 1 & $1.995 \mathrm{E}-02$ & $1.980 \mathrm{E}-01$ & $3.952 \mathrm{E}+08$ \\
\hline & 21208.500 & 119982.260 & $9.001 \mathrm{E}-01$ & 1 & 3 & $5.941 \mathrm{E}-02$ & $1.980 \mathrm{E}-01$ & $1.289 \mathrm{E}+08$ \\
\hline \multirow[t]{7}{*}{$a^{3} P^{e} \rightarrow z^{3} D^{o}$} & 2.0703 & 1.1362 & $9.341 \mathrm{E}-01$ & 9 & 15 & $6.186 \mathrm{E}-05$ & $1.788 \mathrm{E}-03$ & $2.601 \mathrm{E}+05$ \\
\hline & 19404.800 & 122346.610 & $9.381 \mathrm{E}-01$ & 5 & 7 & $5.218 \mathrm{E}-05$ & $8.344 \mathrm{E}-04$ & $2.634 \mathrm{E}+05$ \\
\hline & 19404.800 & 122628.340 & $9.407 \mathrm{E}-01$ & 5 & 5 & $9.344 \mathrm{E}-06$ & $1.490 \mathrm{E}-04$ & $6.641 \mathrm{E}+04$ \\
\hline & 19404.800 & 122843.030 & $9.426 \mathrm{E}-01$ & 5 & 3 & $6.242 \mathrm{E}-07$ & $9.933 \mathrm{E}-06$ & $7.424 \mathrm{E}+03$ \\
\hline & 20688.400 & 122628.340 & $9.290 \mathrm{E}-01$ & 3 & 5 & $4.614 \mathrm{E}-05$ & $4.470 \mathrm{E}-04$ & $1.919 \mathrm{E}+05$ \\
\hline & 20688.400 & 122843.030 & $9.309 \mathrm{E}-01$ & 3 & 3 & $1.541 \mathrm{E}-05$ & $1.490 \mathrm{E}-04$ & $1.073 \mathrm{E}+05$ \\
\hline & 21208.500 & 122843.030 & $9.261 \mathrm{E}-01$ & 1 & 3 & $6.133 \mathrm{E}-05$ & $1.987 \mathrm{E}-04$ & $1.408 \mathrm{E}+05$ \\
\hline \multirow[t]{6}{*}{$a^{3} P^{e} \rightarrow w^{3} D^{o}$} & 2.0703 & 1.0115 & $1.059 \mathrm{E}+00$ & 9 & 15 & $1.354 \mathrm{E}-01$ & $3.454 \mathrm{E}+00$ & $7.318 \mathrm{E}+08$ \\
\hline & 19404.800 & 135705.570 & $1.060 \mathrm{E}+00$ & 5 & 7 & $1.139 \mathrm{E}-01$ & $1.612 \mathrm{E}+00$ & $7.338 \mathrm{E}+08$ \\
\hline & 19404.800 & 136793.820 & $1.070 \mathrm{E}+00$ & 5 & 5 & $2.053 \mathrm{E}-02$ & $2.878 \mathrm{E}-01$ & $1.887 \mathrm{E}+08$ \\
\hline & 19404.800 & 136464.900 & $1.067 \mathrm{E}+00$ & 5 & 3 & $1.365 \mathrm{E}-03$ & $1.919 \mathrm{E}-02$ & $2.079 \mathrm{E}+07$ \\
\hline & 20688.400 & 136793.820 & $1.058 \mathrm{E}+00$ & 3 & 5 & $1.015 \mathrm{E}-01$ & $8.635 \mathrm{E}-01$ & $5.477 \mathrm{E}+08$ \\
\hline & 20688.400 & 136464.900 & $1.055 \mathrm{E}+00$ & 3 & 3 & $3.374 \mathrm{E}-02$ & $2.878 \mathrm{E}-01$ & $3.017 \mathrm{E}+08$ \\
\hline \multirow[t]{2}{*}{$a^{1} G^{e} \rightarrow z^{1} F^{o}$} & 1.9714 & 1.0117 & $9.597 \mathrm{E}-01$ & 9 & 7 & $3.515 \mathrm{E}-03$ & $9.890 \mathrm{E}-02$ & $3.343 \mathrm{E}+07$ \\
\hline & 30886.400 & 136200.130 & $9.596 \mathrm{E}-01$ & 9 & 7 & $3.515 \mathrm{E}-03$ & $9.890 \mathrm{E}-02$ & $3.343 \mathrm{E}+07$ \\
\hline
\end{tabular}

line intensities from observed sources. Many of the observed spectral lines correspond to transitions for which the new $A$-values do not differ significantly from those of Garstang and the two sets of theoretical line ratios agree in about equal degree from the observations. Considering all the other line ratios, the present line ratios in general gave better agreement with observations than the set with Garstang $A$-values.

A few computed and the observed line ratios from different sources are shown in Fig. 1. In Figs. 1a and $\mathrm{b}$ we present two line ratios $I(\lambda 5011) / I(\lambda 4658)$ and $\lambda(4881) /(\lambda 4658)$ observed from the PN IC 4997, at two different epochs 1990 and 1991. Figure 1c shows line ratio $I(2.241 \mu) / I(2.218 \mu)$ from two differnt sources, the Galactic Center and the Orion nebula. The present line ratio $I(\lambda 5011) / I(\lambda 4658)$ (solid line) for IC 4997 is in reasonable agreement with those derived using the Garstang A-values, with somewhat lower electron densities $N_{\mathrm{e}} \approx 10^{3.5}-10^{4.8}$, compared to $N_{\mathrm{e}} \approx 10^{4}-10^{5.5}$, at the two epochs respectively. The present line ratio $\lambda(4881) /(\lambda 4658)$ differs significantly from the one calculated with the Garstang $A$-values; the latter appears to be barely within the range of observed values, whereas the present one overlaps much more with the observations (we employ an electron temperature of $8000 \mathrm{~K}$, close to the temperatures derived by Keenan et al. (1993) from other diagnostic line ratios). However, the observed line ratio $I(2.241 \mu) / I(2.218 \mu)$ from the Galactic Center (Chen $\&$ Werner, private communication) and the Orion nebula (Osterbrock et al. 1992) agree with each other and lie at the lower end of the theoretical line ratio with the present $A$-values, but lie well above those predicted by the set of Garstang $A$-values.

\section{Discussion and conclusion}

Comprehensive calculations for the allowed and the forbidden transition probabilites of Fe III are reported. While an attempt has been made to compare the new $A$-values with previously available data, it is nonetheless difficult to ascertain the precise accuracy due to the fact that very little experimental data is available for the E1 transitions, and none for the E2 and M1 transitions. We expect the present E1 radiative data to be at least as accurate as currently available data, since extensive configuration interaction is included in the close coupling R-matrix calculations and since the relativistic effects for the dipole transitions in Fe III should be small.

The forbidden E2 and M1 radiative data appears to yield theoretical line ratios in better agreement with observations than the earlier Garstang calculations. Nonetheless it should be remarked that Garstang's work entails an 
Table 5. Ground configuration $3 \mathrm{~d}^{6}$ energy levels of Fe III computed in the Breit-Pauli approximation using Superstructure. The scaling parameters $\lambda_{n \ell}$ for the $1 \mathrm{~s}-4 \mathrm{~d}$ Thomas-Fermi orbitals are: 1.0955, 1.0955, 1.0955, 1.0955, 1.072, 1.11, 1.0178, $1.4951,1.5306$. The configuration expansion is: $3 \mathrm{~d}^{6}, 3 \mathrm{~d}^{5} 4 \mathrm{~s}$, $3 \mathrm{~s}^{2} 3 \mathrm{p}^{4} 3 \mathrm{~d}^{8}, 3 \mathrm{p}^{6} 3 \mathrm{~d}^{8}, 3 \mathrm{~s} 3 \mathrm{p}^{6} 3 \mathrm{~d}^{7}, 3 \mathrm{~s}^{2} 3 \mathrm{p}^{6} 3 \mathrm{~d}^{4} 4 \mathrm{~s}^{2}, 3 \mathrm{~s}^{2} 3 \mathrm{p}^{6} 3 \mathrm{~d}^{4} 4 \mathrm{p}^{2}$, $3 \mathrm{~d}^{5} 4 \mathrm{~d}$. Energies are in Rydbergs

\begin{tabular}{|c|c|c|c|c|c|}
\hline Level & & & $E(\mathrm{obs})$ & $E(\mathrm{cal})$ & $E^{\mathrm{a}}$ \\
\hline \multirow[t]{34}{*}{$3 d^{6}$} & $a^{5} D$ & 4 & 0.0 & 0.0 & 0.0 \\
\hline & & 3 & 0.00397 & 0.00431 & 0.00445 \\
\hline & & 2 & 0.00673 & 0.00726 & 0.00756 \\
\hline & & 1 & 0.00850 & 0.00913 & 0.00953 \\
\hline & & 0 & 0.00936 & 0.01004 & 0.01049 \\
\hline & $a^{3} P$ & 2 & 0.17683 & 0.18049 & 0.22715 \\
\hline & & 1 & 0.18853 & 0.19337 & 0.23993 \\
\hline & & 0 & 0.19327 & 0.19844 & 0.24633 \\
\hline & $a^{3} H$ & 6 & 0.18272 & 0.21488 & 0.20751 \\
\hline & & 5 & 0.18499 & 0.21728 & 0.20956 \\
\hline & & 4 & 0.18664 & 0.21934 & 0.21178 \\
\hline & $a^{3} F$ & 4 & 0.19558 & 0.21178 & 0.23813 \\
\hline & & 3 & 0.19774 & 0.21462 & 0.24002 \\
\hline & & 2 & 0.19918 & 0.21616 & 0.24212 \\
\hline & $a^{3} G$ & 5 & 0.22380 & 0.25469 & 0.26198 \\
\hline & & 4 & 0.22728 & 0.25822 & 0.26616 \\
\hline & & 3 & 0.22911 & 0.26019 & 0.26805 \\
\hline & $a^{1} I$ & 6 & 0.27663 & 0.32429 & - \\
\hline & $a^{3} D$ & 3 & 0.28120 & 0.30980 & - \\
\hline & & 2 & 0.27991 & 0.30821 & - \\
\hline & & 1 & 0.27999 & 0.30843 & - \\
\hline & $a^{1} G$ & 4 & 0.28146 & 0.30613 & - \\
\hline & $a^{1} S$ & 0 & 0.31723 & 0.32587 & - \\
\hline & $a^{1} D$ & 2 & 0.32627 & 0.35376 & - \\
\hline & $a^{1} F$ & 3 & 0.39091 & 0.43536 & - \\
\hline & $b^{3} P$ & 0 & 0.44787 & 0.48889 & 0.56042 \\
\hline & & 1 & 0.45178 & 0.49331 & 0.56458 \\
\hline & & 2 & 0.45939 & 0.50176 & 0.56136 \\
\hline & $b^{3} F$ & 2 & 0.45732 & 0.50251 & 0.57294 \\
\hline & & 4 & 0.45815 & 0.50400 & 0.56205 \\
\hline & & 3 & 0.45832 & 0.50390 & 0.56165 \\
\hline & $b^{1} G$ & 4 & 0.52144 & 0.57910 & - \\
\hline & $b^{1} D$ & 2 & 0.70208 & 0.77643 & - \\
\hline & $b^{1} S$ & 0 & 0.93323 & 0.98083 & - \\
\hline
\end{tabular}

a Zhang \& Pradhan (1995)
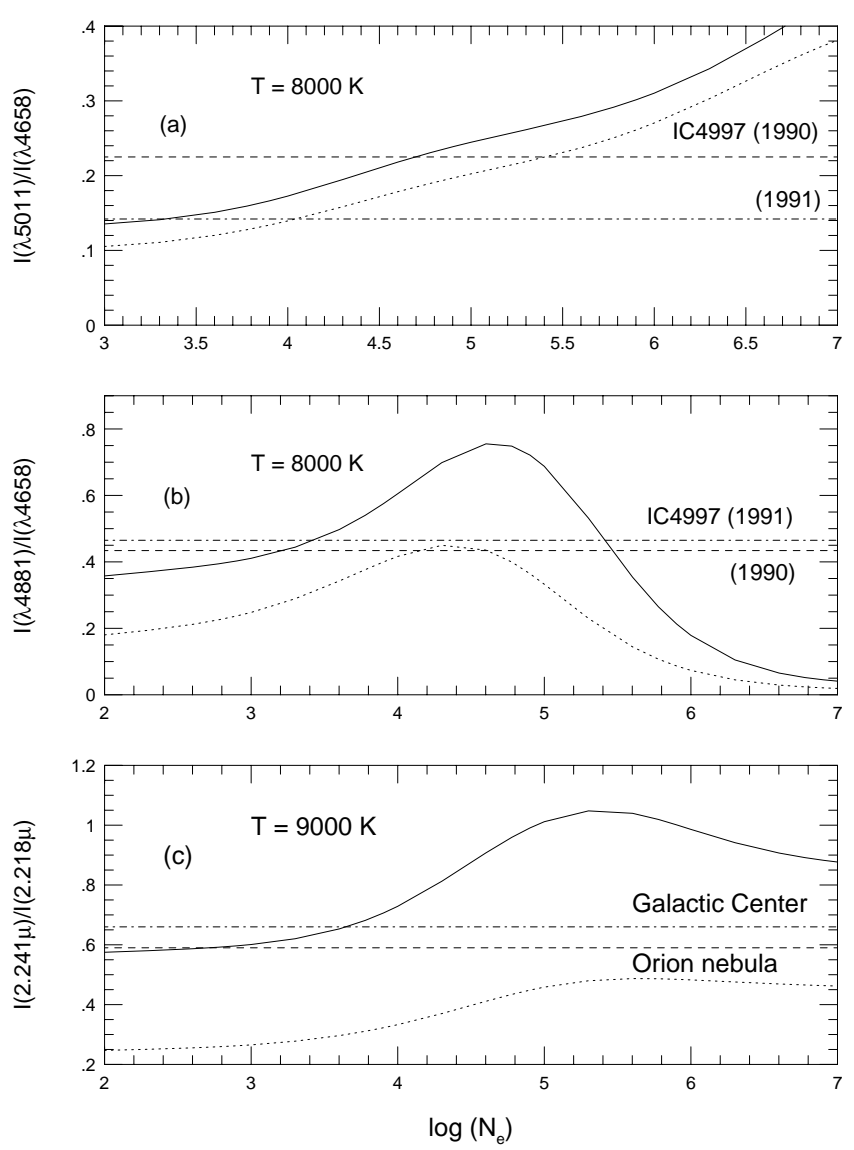

Fig. 1. Theoretical line ratios calculated using the present forbidden E2 and M1 transition probabilities (solid line), and using those by Garstang (small-dashed dotted line), compared with the observed line ratios from the planetary nebula IC 4997 (at two epochs, 1990 and 1991) the Galactic Center, and the Orion nebula (references in the text)

adjustment of the relevant atomic parameters to yield observed term and fine structure energy differences; whereas the present work is entirely ab intio and no such adjustment is made on the grounds that it may alter some matrix elements unphysically. However, the computed energies are close to experimental ones (Table 5 ) and the latter are used in the final calculation of the E2 and M1 probabilities. For a given transition, it is still difficult to assert definitively that Garstang's or the present probabilities should be preferred; on the whole we expect the present dataset to be more complete and accurate.

Extensive spectral diagnostics of the Fe III spectra from a variety of sources in the IR and the Optical is now under way using a Non-LTE collisional-radiative model (Bautista \& Pradhan 1995) and the new sets of collisional and radiative data in this paper and the following one.

We note that a majority of the forbidden transitions of Fe III given in Table 6 lie in the optical and the nearinfrared, unlike Fe II where a majority of the low-lying transitions are in the infra-red. This fact possibly has 
rather important implications for the determination of the ionization structure of nebular objects (including supernova remnants), based on the IR and Optical spectroscopic diagnostics.

Complete tables of transition probabilities may be obtained electronically from nahar@seaton.mps.ohiostate.edu. A FORTRAN77 code is attached to the table of $A(\mathrm{E} 1)$ to read the dipole allowed $A$-values and calculate lifetimes of levels.

Acknowledgements. This work was partially supported by NASA grants NAGW-3315 and NAS-32643 (SNN), and by the US National Science Foundation grant for the Iron Project PHY-9421898 (AKP). We would like to thank Dr. J.O. Ekberg at Lünd and Ms. Arlene Robey at NIST for providing Fe III energy levels in electronic form. We also thank Mr. Manuel Bautista for the calculation of Fe III line ratios and for plotting Fig. 1. The computational work was carried out on the Cray YMP at the Ohio Supercomputer Center in Columbus, Ohio.

\section{References}

Andersen T., Petersen P, Biemont E., 1977, Quant. Spectrosc. Radiat. Transfer 17, 389

Bautista M.A., Pradhan A.K., 1995, J. Phys. B 28, L173

Bautista M.A., 1996, A\&A (submitted)
Biemont E., 1976, JQSRT 16, 137 (1976)

Cowan R.D., 1968, J. Opt. Soc. Am. 58, 808

Eissner W., Jones M., Nussbaumer H., 1974, Comput. Phys. Commun. 8, 270

Ekberg J.O., 1993, A\&AS 101, 1

Fawcett B.C., 1989, At. Data Nucl. Data Tables 41, 181

Garstang R.H., 1957, MNRAS 117, 393

Hummer D.G., Berrington K.A., Eissner W., Pradhan A.K., Saraph H.E., Tully J.A., 1993, A\&A 279, 298

Keenan F.P., Aller L.H., Hyung S., Condon E.S., Warner G.A., 1993, ApJ 410, 430

Kurucz R.L., Peytremann E., 1975, Tables of semiempirical $g f$ values, Smithsonian Astrophysical Observatory Special Report 362

Nahar S.N., 1996, Phys. Rev. A 53, 1545 (N1)

Nahar S.N., 1996, Phys. Rev. A 53, 2417

Nahar S.N., 1995, A\&A 293, 6363

Nahar S.N., 1993, Phys. Scripta 48, 297

Nahar S.N., 1996, Phys. Scripta (in press) (N2)

Nussbaumer H., Storey P.J., 1978, A\&A 64, 139

Osterbrock D.E., Tran H.D., Villeux S., 1992, ApJ 389, 305

Sawey P.M.J., Berrington K.A., 1992, J. Phys. B 25, 1451

Seaton M.J., 1987, J. Phys. B 20, 6363

Sugar J., Corliss C., 1985, J. Phys. Chem. Ref. Data 14, Suppl. 2

Zhang H.L., Pradhan A.K., 1995, J. Phys. B 28, 3403

Zhang H.L., 1996, A\&A, (in press) 
Table 6. E2 and M1 $A$-coefficients for forbidden transitions in Fe III

\begin{tabular}{|c|c|c|c|}
\hline Transition & $\lambda(\mathrm{obs} ; \mu)$ & $A(\mathrm{E} 2)$ & $A(\mathrm{M} 1)$ \\
\hline$D_{3}-a^{5} D_{4}$ & 22.9253 & 6.27 & 2.8 \\
\hline$a^{5} D_{2}-a^{5} D_{4}$ & 13.5336 & $2.81 \mathrm{E}-09$ & $0.00 \mathrm{E}+00$ \\
\hline$a^{5} D_{2}-a^{5} D_{3}$ & 33.0360 & $1.01 \mathrm{E}-10$ & $1.79 \mathrm{E}-03$ \\
\hline$a^{5} D_{1}-a^{5} D_{3}$ & 20.1532 & $1.05 \mathrm{E}-09$ & $0.00 \mathrm{E}+00$ \\
\hline$a^{5} D_{1}-a^{5} D_{2}$ & 51.6796 & $5.89 \mathrm{E}-12$ & $6.82 \mathrm{E}-04$ \\
\hline$a^{3} P_{2}-a^{5} D_{4}$ & 0.5153 & $5.93 \mathrm{E}-06$ & $0.00 \mathrm{E}+00$ \\
\hline$a^{3} P_{2}-a^{5} D_{3}$ & 0.5272 & $1.17 \mathrm{E}-04$ & $5.08 \mathrm{E}-01$ \\
\hline$a^{3} P_{2}-a^{5} D_{2}$ & 0.5357 & 7.92E-06 & $5.20 \mathrm{E}-05$ \\
\hline$a^{3} P_{2}-a^{5} D_{1}$ & 0.5413 & $2.05 \mathrm{E}-05$ & 4.91E-02 \\
\hline$a^{3} P_{2}-a^{5} D_{0}$ & 0.5441 & $2.53 \mathrm{E}-05$ & $0.00 \mathrm{E}+00$ \\
\hline$a^{3} P_{1}-a^{5} D_{3}$ & 0.4938 & $7.12 \mathrm{E}-05$ & $0.00 \mathrm{E}+00$ \\
\hline$a^{3} P_{1}-a^{5} D_{2}$ & 0.5013 & $1.23 \mathrm{E}-04$ & $6.32 \mathrm{E}-01$ \\
\hline$a^{3} P_{1}-a^{5} D_{1}$ & 0.5062 & $1.19 \mathrm{E}-04$ & $4.07 \mathrm{E}-05$ \\
\hline$a^{3} P_{1}-a^{5} D_{0}$ & 0.5086 & $0.00 \mathrm{E}+00$ & $1.10 \mathrm{E}-01$ \\
\hline$a^{3} P_{1}-a^{3} P_{2}$ & 7.7906 & $1.65 \mathrm{E}-10$ & 4.77E-02 \\
\hline$a^{3} P_{0}-a^{5} D_{2}$ & 0.4885 & $4.20 \mathrm{E}-04$ & $0.00 \mathrm{E}+00$ \\
\hline$a^{3} P_{0}-a^{5} D_{1}$ & 0.4932 & $0.00 \mathrm{E}+00$ & $8.13 \mathrm{E}-01$ \\
\hline$a^{3} P_{0}-a^{3} P_{1}$ & 19.2271 & $0.00 \mathrm{E}+00$ & $7.54 \mathrm{E}-03$ \\
\hline$a^{3} F_{4}-a^{5} D_{4}$ & 0.4659 & $8.42 \mathrm{E}-05$ & 4.30E-01 \\
\hline$a^{3} F_{4}-a^{5} D_{3}$ & 0.4756 & $3.96 \mathrm{E}-05$ & 8.23E-02 \\
\hline$a^{3} F_{4}-a^{5} D_{2}$ & 0.4825 & $1.37 \mathrm{E}-05$ & $0.00 \mathrm{E}+00$ \\
\hline$a^{3} F_{4}-a^{3} P_{2}$ & 4.8605 & $2.94 \mathrm{E}-07$ & $0.00 \mathrm{E}+00$ \\
\hline$a^{3} F_{3}-a^{5} D_{4}$ & 0.4608 & $3.23 \mathrm{E}-05$ & $4.24 \mathrm{E}-02$ \\
\hline$a^{3} F_{3}-a^{5} D_{3}$ & 0.4703 & $6.17 \mathrm{E}-06$ & $2.32 \mathrm{E}-01$ \\
\hline$a^{3} F_{3}-a^{5} D_{2}$ & 0.4771 & $3.78 \mathrm{E}-05$ & 8.13E-02 \\
\hline$a^{3} F_{3}-a^{5} D_{1}$ & 0.4815 & $1.87 \mathrm{E}-05$ & $0.00 \mathrm{E}+00$ \\
\hline$a^{3} F_{3}-a^{3} P_{2}$ & 4.3571 & $1.31 \mathrm{E}-07$ & $1.40 \mathrm{E}-06$ \\
\hline$a^{3} F_{3}-a^{3} P_{1}$ & 9.8863 & $5.53 \mathrm{E}-09$ & $0.00 \mathrm{E}+00$ \\
\hline$a^{3} F_{3}-a^{3} F_{4}$ & 42.0698 & $9.83 \mathrm{E}-15$ & 3.39E-04 \\
\hline$a^{3} H_{6}-a^{5} D_{4}$ & 0.4987 & $4.27 \mathrm{E}-06$ & $0.00 \mathrm{E}+00$ \\
\hline$a^{3} F_{2}-a^{5} D_{4}$ & 0.4575 & $2.42 \mathrm{E}-06$ & $0.00 \mathrm{E}+00$ \\
\hline$a^{3} F_{2}-a^{5} D_{3}$ & 0.4668 & $8.96 \mathrm{E}-06$ & $2.56 \mathrm{E}-02$ \\
\hline$a^{3} F_{2}-a^{5} D_{2}$ & 0.4735 & $3.06 \mathrm{E}-07$ & $9.04 \mathrm{E}-02$ \\
\hline$a^{3} F_{2}-a^{5} D_{1}$ & 0.4779 & $2.71 \mathrm{E}-05$ & 4.41E-02 \\
\hline$a^{3} F_{2}-a^{5} D_{0}$ & 0.4801 & $1.96 \mathrm{E}-05$ & $0.00 \mathrm{E}+00$ \\
\hline$a^{3} F_{2}-a^{3} P_{2}$ & 4.0776 & $2.73 \mathrm{E}-08$ & $8.12 \mathrm{E}-06$ \\
\hline$a^{3} F_{2}-a^{3} P_{1}$ & 8.5558 & $6.20 \mathrm{E}-09$ & $1.16 \mathrm{E}-07$ \\
\hline$a^{3} F_{2}-a^{3} P_{0}$ & 15.4154 & $3.84 \mathrm{E}-10$ & $0.00 \mathrm{E}+00$ \\
\hline$a^{3} F_{2}-a^{3} F_{3}$ & 63.5728 & $3.14 \mathrm{E}-14$ & $1.38 \mathrm{E}-04$ \\
\hline$a^{3} H_{5}-a^{5} D_{4}$ & 0.4926 & $4.28 \mathrm{E}-06$ & $6.25 \mathrm{E}-06$ \\
\hline$a^{3} H_{5}-a^{5} D_{3}$ & 0.5034 & $2.50 \mathrm{E}-06$ & $0.00 \mathrm{E}+00$ \\
\hline$a^{3} H_{5}-a^{3} F_{4}$ & 8.6103 & $2.29 \mathrm{E}-08$ & $3.20 \mathrm{E}-03$ \\
\hline$a^{3} H_{5}-a^{3} H_{6}$ & 40.0481 & $3.37 \mathrm{E}-12$ & 4.05E-04 \\
\hline$a^{3} H_{4}-a^{5} D_{4}$ & 0.4882 & $4.29 \mathrm{E}-06$ & $9.62 \mathrm{E}-03$ \\
\hline$a^{3} H_{4}-a^{5} D_{3}$ & 0.4989 & $1.34 \mathrm{E}-07$ & $1.92 \mathrm{E}-03$ \\
\hline$a^{3} H_{4}-a^{5} D_{2}$ & 0.5065 & $1.32 \mathrm{E}-07$ & $0.00 \mathrm{E}+00$ \\
\hline$a^{3} H_{4}-a^{3} P_{2}$ & 9.2842 & $2.95 \mathrm{E}-10$ & $0.00 \mathrm{E}+00$ \\
\hline$a^{3} H_{4}-a^{3} F_{4}$ & 10.2010 & $3.97 \mathrm{E}-12$ & $5.82 \mathrm{E}-03$ \\
\hline$a^{3} H_{4}-a^{3} F_{3}$ & 8.2102 & $2.50 \mathrm{E}-08$ & 2.83E-03 \\
\hline$a^{3} H_{4}-a^{3} H_{5}$ & 55.2181 & $3.38 \mathrm{E}-13$ & $1.85 \mathrm{E}-04$ \\
\hline$a^{3} G_{5}-a^{5} D_{4}$ & 0.4072 & $1.28 \mathrm{E}-04$ & $2.58 \mathrm{E}-04$ \\
\hline$a^{3} G_{5}-a^{5} D_{3}$ & 0.4145 & $2.56 \mathrm{E}-05$ & $0.00 \mathrm{E}+00$ \\
\hline$a^{3} G_{5}-a^{3} F_{4}$ & 3.2293 & $1.14 \mathrm{E}-06$ & 7.94E-03 \\
\hline$a^{3} G_{5}-a^{3} F_{3}$ & 3.4978 & $2.63 \mathrm{E}-07$ & $0.00 \mathrm{E}+00$ \\
\hline$a^{3} G_{5}-a^{3} H_{6}$ & 2.2184 & $1.00 \mathrm{E}-04$ & $4.11 \mathrm{E}-02$ \\
\hline$a^{3} G_{5}-a^{3} H_{5}$ & 2.3485 & $1.14 \mathrm{E}-05$ & 2.89E-02 \\
\hline
\end{tabular}

Table 6. continued

\begin{tabular}{|c|c|c|c|}
\hline Transition & $\lambda(\mathrm{obs} ; \mu)$ & $A(\mathrm{E} 2)$ & $A(\mathrm{M} 1)$ \\
\hline${ }^{3} G_{5}-a^{3} H_{4}$ & 2.4528 & $1.21 \mathrm{E}-06$ & $4.17 \mathrm{E}-03$ \\
\hline$a^{3} G_{4}-a^{5} D_{4}$ & 0.4009 & $4.49 \mathrm{E}-05$ & $2.88 \mathrm{E}-03$ \\
\hline$a^{3} G_{4}-a^{5} D_{3}$ & 0.4081 & $6.71 \mathrm{E}-05$ & $9.41 \mathrm{E}-04$ \\
\hline$a^{3} G_{4}-a^{5} D_{2}$ & 0.4132 & $2.44 \mathrm{E}-05$ & $0.00 \mathrm{E}+00$ \\
\hline$a^{3} G_{4}-a^{3} P_{2}$ & 1.8063 & 3.64E-08 & $0.00 \mathrm{E}+00$ \\
\hline$a^{3} G_{4}-a^{3} F_{4}$ & 2.8746 & $1.13 \mathrm{E}-06$ & $8.08 \mathrm{E}-03$ \\
\hline$a^{3} G_{4}-a^{3} F_{3}$ & 3.0855 & $1.14 \mathrm{E}-06$ & 3.59E-09 \\
\hline$a^{3} G_{4}-a^{3} H_{6}$ & 2.0451 & $1.98 \mathrm{E}-05$ & $0.00 \mathrm{E}+00$ \\
\hline$a^{3} G_{4}-a^{3} F_{2}$ & 3.2429 & 3.77E-07 & $0.00 \mathrm{E}+00$ \\
\hline$a^{3} G_{4}-a^{3} H_{5}$ & 2.1551 & $9.52 \mathrm{E}-05$ & $1.68 \mathrm{E}-04$ \\
\hline$a^{3} G_{4}-a^{3} H_{4}$ & 2.2427 & $1.35 \mathrm{E}-05$ & $4.58 \mathrm{E}-02$ \\
\hline$a^{3} G_{4}-a^{3} G_{5}$ & 26.1712 & $1.83 \mathrm{E}-11$ & $1.45 \mathrm{E}-03$ \\
\hline$a^{3} G_{3}-a^{5} D_{4}$ & 0.3977 & $4.11 \mathrm{E}-06$ & $1.72 \mathrm{E}-04$ \\
\hline$a^{3} G_{3}-a^{5} D_{3}$ & 0.4048 & $2.30 \mathrm{E}-05$ & $1.24 \mathrm{E}-03$ \\
\hline$a^{3} G_{3}-a^{5} D_{2}$ & 0.4098 & 3.03E-05 & $5.47 \mathrm{E}-04$ \\
\hline$a^{3} G_{3}-a^{5} D_{1}$ & 0.4131 & $1.36 \mathrm{E}-05$ & $0.00 \mathrm{E}+00$ \\
\hline$a^{3} G_{3}-a^{3} P_{2}$ & 1.7429 & $1.34 \mathrm{E}-09$ & $4.00 \mathrm{E}-07$ \\
\hline$a^{3} G_{3}-a^{3} P_{1}$ & 2.2452 & 3.92E-09 & $0.00 \mathrm{E}+00$ \\
\hline$a^{3} G_{3}-a^{3} F_{4}$ & 2.7172 & $4.52 \mathrm{E}-07$ & $3.24 \mathrm{E}-03$ \\
\hline$a^{3} G_{3}-a^{3} F_{3}$ & 2.9049 & 7.01E-07 & $1.60 \mathrm{E}-02$ \\
\hline$a^{3} G_{3}-a^{3} F_{2}$ & 3.0440 & $1.65 \mathrm{E}-06$ & $1.00 \mathrm{E}-02$ \\
\hline$a^{3} G_{3}-a^{3} H_{5}$ & 2.0654 & $2.20 \mathrm{E}-05$ & $0.00 \mathrm{E}+00$ \\
\hline$a^{3} G_{3}-a^{3} H_{4}$ & 2.1457 & $1.14 \mathrm{E}-04$ & $3.68 \mathrm{E}-02$ \\
\hline$a^{3} G_{3}-a^{3} G_{4}$ & 49.6278 & $7.27 \mathrm{E}-13$ & $2.71 \mathrm{E}-04$ \\
\hline$a^{1} G_{4}-a^{5} D_{4}$ & 0.3238 & $1.37 \mathrm{E}-06$ & $6.12 \mathrm{E}-04$ \\
\hline$a^{1} G_{4}-a^{5} D_{3}$ & 0.3284 & $5.48 \mathrm{E}-07$ & $1.21 \mathrm{E}-04$ \\
\hline$a^{1} G_{4}-a^{5} D_{2}$ & 0.3317 & $2.78 \mathrm{E}-07$ & $0.00 \mathrm{E}+00$ \\
\hline$a^{1} G_{4}-a^{3} P_{2}$ & 0.8710 & $2.34 \mathrm{E}-06$ & $0.00 \mathrm{E}+00$ \\
\hline$a^{1} G_{4}-a^{3} F_{4}$ & 1.0611 & $5.27 \mathrm{E}-07$ & $1.26 \mathrm{E}-01$ \\
\hline$a^{1} G_{4}-a^{3} F_{3}$ & 1.0886 & $5.87 \mathrm{E}-07$ & $9.87 \mathrm{E}-02$ \\
\hline$a^{1} G_{4}-a^{3} H_{6}$ & 0.9229 & $1.39 \mathrm{E}-05$ & $0.00 \mathrm{E}+00$ \\
\hline$a^{1} G_{4}-a^{3} F_{2}$ & 1.1075 & $1.03 \mathrm{E}-07$ & $0.00 \mathrm{E}+00$ \\
\hline$a^{1} G_{4}-a^{3} H_{5}$ & 0.9447 & $9.56 \mathrm{E}-06$ & $2.45 \mathrm{E}-01$ \\
\hline$a^{1} G_{4}-a^{3} H_{4}$ & 0.9611 & $1.18 \mathrm{E}-05$ & $2.15 \mathrm{E}-01$ \\
\hline$a^{1} G_{4}-a^{3} G_{5}$ & 1.5804 & $1.05 \mathrm{E}-07$ & $2.15 \mathrm{E}-05$ \\
\hline$a^{1} G_{4}-a^{3} G_{4}$ & 1.6819 & $5.47 \mathrm{E}-07$ & $3.09 \mathrm{E}-07$ \\
\hline$a^{1} G_{4}-a^{3} G_{3}$ & 1.7409 & $8.77 \mathrm{E}-07$ & $1.81 \mathrm{E}-04$ \\
\hline$a^{3} D_{2}-a^{5} D_{4}$ & 0.3256 & $2.63 \mathrm{E}-04$ & $0.00 \mathrm{E}+00$ \\
\hline$a^{3} D_{2}-a^{5} D_{3}$ & 0.3303 & $2.50 \mathrm{E}-05$ & $2.59 \mathrm{E}-02$ \\
\hline$a^{3} D_{2}-a^{5} D_{2}$ & 0.3336 & 3.30E-04 & $9.49 \mathrm{E}-02$ \\
\hline$a^{3} D_{2}-a^{5} D_{1}$ & 0.3358 & $2.11 \mathrm{E}-07$ & $8.30 \mathrm{E}-02$ \\
\hline$a^{3} D_{2}-a^{5} D_{0}$ & 0.3368 & $8.29 \mathrm{E}-05$ & $0.00 \mathrm{E}+00$ \\
\hline$a^{3} D_{2}-a^{3} P_{2}$ & 0.8841 & $5.02 \mathrm{E}-04$ & $3.98 \mathrm{E}-02$ \\
\hline$a^{3} D_{2}-a^{3} P_{1}$ & 0.9972 & $2.76 \mathrm{E}-05$ & $1.88 \mathrm{E}-06$ \\
\hline$a^{3} D_{2}-a^{3} P_{0}$ & 1.0518 & $9.56 \mathrm{E}-05$ & $0.00 \mathrm{E}+00$ \\
\hline$a^{3} D_{2}-a^{3} F_{4}$ & 1.0806 & $1.52 \mathrm{E}-03$ & $0.00 \mathrm{E}+00$ \\
\hline$a^{3} D_{2}-a^{3} F_{3}$ & 1.1091 & $1.79 \mathrm{E}-03$ & $2.38 \mathrm{E}-03$ \\
\hline$a^{3} D_{2}-a^{3} F_{2}$ & 1.1288 & $1.15 \mathrm{E}-03$ & $2.39 \mathrm{E}-03$ \\
\hline$a^{3} D_{2}-a^{3} H_{4}$ & 0.9771 & $1.43 \mathrm{E}-05$ & $0.00 \mathrm{E}+00$ \\
\hline$a^{3} D_{2}-a^{3} G_{4}$ & 1.7315 & $3.52 \mathrm{E}-04$ & $0.00 \mathrm{E}+00$ \\
\hline$a^{3} D_{2}-a^{3} G_{3}$ & 1.7941 & 8.37E-05 & $1.44 \mathrm{E}-05$ \\
\hline$a^{3} D_{1}-a^{5} D_{3}$ & 0.3301 & $6.48 \mathrm{E}-05$ & $0.00 \mathrm{E}+00$ \\
\hline$a^{3} D_{1}-a^{5} D_{2}$ & 0.3335 & $5.42 \mathrm{E}-05$ & $1.10 \mathrm{E}-03$ \\
\hline$a^{3} D_{1}-a^{5} D_{1}$ & 0.3356 & $2.72 \mathrm{E}-04$ & $1.24 \mathrm{E}-01$ \\
\hline$a^{3} D_{1}-a^{5} D_{0}$ & 0.3367 & $0.00 \mathrm{E}+00$ & $1.10 \mathrm{E}-01$ \\
\hline
\end{tabular}


Table 6. continued

\begin{tabular}{|c|c|c|c|}
\hline Transition & $\lambda(\mathrm{obs} ; \mu)$ & $A(\mathrm{E} 2)$ & $A(\mathrm{M} 1)$ \\
\hline$a^{3} D_{1}-a^{3} P_{2}$ & 0.8833 & 2.30 & 2 \\
\hline$a^{3} D_{1}-a^{3} P_{1}$ & 0.9963 & 2.92E-04 & $4.25 \mathrm{E}-02$ \\
\hline$a^{3} D_{1}-a^{3} P_{0}$ & 1.0507 & $0.00 \mathrm{E}+00$ & $1.17 \mathrm{E}-02$ \\
\hline$a^{3} D_{1}-a^{3} F_{3}$ & 1.1079 & $1.87 \mathrm{E}-03$ & $0.00 \mathrm{E}+00$ \\
\hline$a^{3} D_{1}-a^{3} F_{2}$ & 1.1276 & $2.59 \mathrm{E}-03$ & $5.17 \mathrm{E}-03$ \\
\hline$a^{3} D_{1}-a^{3} G_{3}$ & 1.7910 & $3.62 \mathrm{E}-04$ & $0.00 \mathrm{E}+00$ \\
\hline$a^{3} D_{3}-a^{5} D_{4}$ & 0.3241 & $8.29 \mathrm{E}-04$ & $1.96 \mathrm{E}-01$ \\
\hline$a^{3} D_{3}-a^{5} D_{3}$ & 0.3287 & 3.77E-04 & $5.56 \mathrm{E}-02$ \\
\hline$a^{3} D_{3}-a^{5} D_{2}$ & 0.3320 & $7.21 \mathrm{E}-07$ & $4.12 \mathrm{E}-02$ \\
\hline$a^{3} D_{3}-a^{5} D_{1}$ & 0.3342 & $4.84 \mathrm{E}-05$ & $0.00 \mathrm{E}+00$ \\
\hline$a^{3} D_{3}-a^{3} P_{2}$ & 0.8731 & $5.38 \mathrm{E}-04$ & $3.44 \mathrm{E}-02$ \\
\hline$a^{3} D_{3}-a^{3} P_{1}$ & 0.9833 & $1.40 \mathrm{E}-04$ & $0.00 \mathrm{E}+00$ \\
\hline$a^{3} D_{3}-a^{3} F_{4}$ & 1.0643 & $3.26 \mathrm{E}-03$ & 8.93E-03 \\
\hline$a^{3} D_{3}-a^{3} F_{3}$ & 1.0920 & $9.48 \mathrm{E}-04$ & $6.41 \mathrm{E}-03$ \\
\hline$a^{3} D_{3}-a^{3} F_{2}$ & 1.1110 & $9.08 \mathrm{E}-05$ & $1.49 \mathrm{E}-03$ \\
\hline$a^{3} D_{3}-a^{3} H_{5}$ & 0.9472 & $2.27 \mathrm{E}-04$ & $0.00 \mathrm{E}+00$ \\
\hline$a^{3} D_{3}-a^{3} H_{4}$ & 0.9638 & $3.06 \mathrm{E}-04$ & $2.92 \mathrm{E}-04$ \\
\hline$a^{3} D_{3}-a^{3} G_{5}$ & 1.5876 & $6.46 \mathrm{E}-04$ & $0.00 \mathrm{E}+00$ \\
\hline$a^{3} D_{3}-a^{3} G_{4}$ & 1.6901 & $9.61 \mathrm{E}-05$ & $9.76 \mathrm{E}-06$ \\
\hline$a^{3} D_{3}-a^{3} G_{3}$ & 1.7497 & 7.64E-06 & $1.03 \mathrm{E}-04$ \\
\hline$a^{3} D_{3}-a^{1} G_{4}$ & 349.6503 & $3.82 \mathrm{E}-18$ & $3.53 \mathrm{E}-12$ \\
\hline$a^{3} D_{3}-a^{3} D_{2}$ & 70.6215 & $2.95 \mathrm{E}-14$ & $5.01 \mathrm{E}-05$ \\
\hline$a^{1} I_{6}-a^{5} D_{4}$ & 0.3294 & $3.39 \mathrm{E}-07$ & $0.00 \mathrm{E}+00$ \\
\hline$a^{1} I_{6}-a^{3} F_{4}$ & 1.1244 & $2.78 \mathrm{E}-06$ & $0.00 \mathrm{E}+00$ \\
\hline$a^{1} I_{6}-a^{3} H_{6}$ & 0.9704 & $2.04 \mathrm{E}-06$ & $6.73 \mathrm{E}-02$ \\
\hline$a^{1} I_{6}-a^{3} H_{5}$ & 0.9945 & $6.38 \mathrm{E}-07$ & $4.41 \mathrm{E}-02$ \\
\hline$a^{1} I_{6}-a^{3} H_{4}$ & 1.0127 & $2.27 \mathrm{E}-07$ & $0.00 \mathrm{E}+00$ \\
\hline$a^{1} I_{6}-a^{3} G_{5}$ & 1.7249 & $6.27 \mathrm{E}-07$ & $1.53 \mathrm{E}-04$ \\
\hline$a^{1} I_{6}-a^{3} G_{4}$ & 1.8466 & 2.99E-09 & $0.00 \mathrm{E}+00$ \\
\hline$a^{1} I_{6}-a^{1} G_{4}$ & 18.8608 & $6.67 \mathrm{E}-10$ & $0.00 \mathrm{E}+00$ \\
\hline$a^{1} S_{0}-a^{5} D_{2}$ & 0.2935 & $4.52 \mathrm{E}-05$ & $0.00 \mathrm{E}+00$ \\
\hline$a^{1} S_{0}-a^{5} D_{1}$ & 0.2952 & $0.00 \mathrm{E}+00$ & $4.76 \mathrm{E}-04$ \\
\hline$a^{1} S_{0}-a^{3} P_{2}$ & 0.6490 & $2.40 \mathrm{E}-04$ & $0.00 \mathrm{E}+00$ \\
\hline$a^{1} S_{0}-a^{3} P_{1}$ & 0.7080 & $0.00 \mathrm{E}+00$ & $1.38 \mathrm{E}+00$ \\
\hline$a^{1} S_{0}-a^{3} F_{2}$ & 0.7719 & $6.82 \mathrm{E}-06$ & $0.00 \mathrm{E}+00$ \\
\hline$a^{1} S_{0}-a^{3} D_{2}$ & 2.4413 & $1.95 \mathrm{E}-06$ & $0.00 \mathrm{E}+00$ \\
\hline$a^{1} S_{0}-a^{3} D_{1}$ & 2.4470 & $0.00 \mathrm{E}+00$ & $1.99 \mathrm{E}-05$ \\
\hline$a^{1} D_{2}-a^{5} D_{4}$ & 0.2793 & $4.80 \mathrm{E}-06$ & $0.00 \mathrm{E}+00$ \\
\hline$a^{1} D_{2}-a^{5} D_{3}$ & 0.2827 & $1.37 \mathrm{E}-07$ & $1.33 \mathrm{E}-04$ \\
\hline$a^{1} D_{2}-a^{5} D_{2}$ & 0.2852 & $3.28 \mathrm{E}-06$ & $1.45 \mathrm{E}-03$ \\
\hline$a^{1} D_{2}-a^{5} D_{1}$ & 0.2868 & $2.68 \mathrm{E}-06$ & 8.57E-04 \\
\hline$a^{1} D_{2}-a^{5} D_{0}$ & 0.2876 & $1.47 \mathrm{E}-07$ & $0.00 \mathrm{E}+00$ \\
\hline$a^{1} D_{2}-a^{3} P_{2}$ & 0.6098 & 2.17E-05 & 7.91E-02 \\
\hline$a^{1} D_{2}-a^{3} P_{1}$ & 0.6616 & $2.84 \mathrm{E}-05$ & $2.83 \mathrm{E}-02$ \\
\hline$a^{1} D_{2}-a^{3} P_{0}$ & 0.6852 & $4.50 \mathrm{E}-05$ & $0.00 \mathrm{E}+00$ \\
\hline$a^{1} D_{2}-a^{3} F_{4}$ & 0.6973 & $2.72 \mathrm{E}-06$ & $0.00 \mathrm{E}+00$ \\
\hline$a^{1} D_{2}-a^{3} F_{3}$ & 0.7090 & $3.12 \mathrm{E}-04$ & $2.25 \mathrm{E}-01$ \\
\hline$a^{1} D_{2}-a^{3} F_{2}$ & 0.7170 & $4.48 \mathrm{E}-06$ & $1.23 \mathrm{E}-01$ \\
\hline$a^{1} D_{2}-a^{3} H_{4}$ & 0.6527 & $1.41 \mathrm{E}-04$ & $0.00 \mathrm{E}+00$ \\
\hline$a^{1} D_{2}-a^{3} G_{4}$ & 0.9206 & $1.10 \mathrm{E}-04$ & $0.00 \mathrm{E}+00$ \\
\hline$a^{1} D_{2}-a^{3} G_{3}$ & 0.9380 & $4.71 \mathrm{E}-05$ & $1.15 \mathrm{E}-03$ \\
\hline$a^{1} D_{2}-a^{1} G_{4}$ & 2.0336 & $8.47 \mathrm{E}-05$ & $0.00 \mathrm{E}+00$ \\
\hline$a^{1} D_{2}-a^{3} D_{2}$ & 1.9656 & $1.69 \mathrm{E}-06$ & 8.47E-03 \\
\hline$a^{1} D_{2}-a^{3} D_{1}$ & 1.9693 & $3.04 \mathrm{E}-07$ & $4.65 \mathrm{E}-02$ \\
\hline$a^{1} D_{2}-a^{3} D_{3}$ & 2.0219 & $1.27 \mathrm{E}-06$ & $4.51 \mathrm{E}-02$ \\
\hline
\end{tabular}

Table 6. continued

\begin{tabular}{|c|c|c|c|}
\hline Transition & $\lambda(\mathrm{obs} ; \mu)$ & $A(\mathrm{E} 2)$ & $A(\mathrm{M} 1)$ \\
\hline$a^{1} D_{2}-a^{1} S_{0}$ & 10.0878 & $1.74 \mathrm{E}-08$ & $0.00 \mathrm{E}+00$ \\
\hline$a^{1} F_{3}-a^{5} D_{4}$ & 0.2331 & $6.76 \mathrm{E}-06$ & $2.35 \mathrm{E}-04$ \\
\hline$a^{1} F_{3}-a^{5} D_{3}$ & 0.2355 & $8.32 \mathrm{E}-06$ & $7.09 \mathrm{E}-04$ \\
\hline$a^{1} F_{3}-a^{5} D_{2}$ & 0.2372 & $2.60 \mathrm{E}-06$ & $2.61 \mathrm{E}-04$ \\
\hline$a^{1} F_{3}-a^{5} D_{1}$ & 0.2383 & $1.86 \mathrm{E}-06$ & $0.00 \mathrm{E}+00$ \\
\hline$a^{1} F_{3}-a^{3} P_{2}$ & 0.4257 & $1.65 \mathrm{E}-06$ & $2.28 \mathrm{E}-04$ \\
\hline$a^{1} F_{3}-a^{3} P_{1}$ & 0.4503 & $1.52 \mathrm{E}-04$ & $0.00 \mathrm{E}+00$ \\
\hline$a^{1} F_{3}-a^{3} F_{4}$ & 0.4665 & $1.46 \mathrm{E}-03$ & $2.25 \mathrm{E}-03$ \\
\hline$a^{1} F_{3}-a^{3} F_{3}$ & 0.4718 & $1.67 \mathrm{E}-03$ & $7.57 \mathrm{E}-04$ \\
\hline$a^{1} F_{3}-a^{3} F_{2}$ & 0.4753 & $1.46 \mathrm{E}-03$ & $1.12 \mathrm{E}-03$ \\
\hline$a^{1} F_{3}-a^{3} H_{5}$ & 0.4426 & $4.96 \mathrm{E}-03$ & $0.00 \mathrm{E}+00$ \\
\hline$a^{1} F_{3}-a^{3} H_{4}$ & 0.4461 & $1.13 \mathrm{E}-03$ & $1.65 \mathrm{E}-03$ \\
\hline$a^{1} F_{3}-a^{3} G_{5}$ & 0.5453 & $3.25 \mathrm{E}-04$ & $0.00 \mathrm{E}+00$ \\
\hline$a^{1} F_{3}-a^{3} G_{4}$ & 0.5569 & $1.11 \mathrm{E}-03$ & $1.07 \mathrm{E}-01$ \\
\hline$a^{1} F_{3}-a^{3} G_{3}$ & 0.5632 & 3.77E-04 & $5.31 \mathrm{E}-02$ \\
\hline$a^{1} F_{3}-a^{1} G_{4}$ & 0.8326 & $6.66 \mathrm{E}-03$ & $2.83 \mathrm{E}-07$ \\
\hline$a^{1} F_{3}-a^{3} D_{2}$ & 0.8210 & $1.83 \mathrm{E}-04$ & $3.14 \mathrm{E}-02$ \\
\hline$a^{1} F_{3}-a^{3} D_{1}$ & 0.8216 & $1.15 \mathrm{E}-05$ & $0.00 \mathrm{E}+00$ \\
\hline$a^{1} F_{3}-a^{3} D_{3}$ & 0.8306 & $1.81 \mathrm{E}-05$ & $5.36 \mathrm{E}-02$ \\
\hline$a^{1} F_{3}-a^{1} D_{2}$ & 1.4098 & 7.89E-04 & $1.76 \mathrm{E}-05$ \\
\hline$b^{3} P_{0}-a^{5} D_{2}$ & 0.2066 & $2.84 \mathrm{E}-02$ & $0.00 \mathrm{E}+00$ \\
\hline$b^{3} P_{0}-a^{5} D_{1}$ & 0.2074 & $0.00 \mathrm{E}+00$ & $4.22 \mathrm{E}-01$ \\
\hline$b^{3} P_{0}-a^{3} P_{2}$ & 0.3362 & $1.36 \mathrm{E}+00$ & $0.00 \mathrm{E}+00$ \\
\hline$b^{3} P_{0}-a^{3} P_{1}$ & 0.3514 & $0.00 \mathrm{E}+00$ & $1.17 \mathrm{E}-02$ \\
\hline$b^{3} P_{0}-a^{3} F_{2}$ & 0.3664 & $8.72 \mathrm{E}-02$ & $0.00 \mathrm{E}+00$ \\
\hline$b^{3} P_{0}-a^{3} D_{2}$ & 0.5425 & $3.52 \mathrm{E}-01$ & $0.00 \mathrm{E}+00$ \\
\hline$b^{3} P_{0}-a^{3} D_{1}$ & 0.5428 & $0.00 \mathrm{E}+00$ & 7.03E-02 \\
\hline$b^{3} P_{0}-a^{1} D_{2}$ & 0.7494 & $1.55 \mathrm{E}-03$ & $0.00 \mathrm{E}+00$ \\
\hline$b^{3} P_{1}-a^{5} D_{3}$ & 0.2035 & $3.06 \mathrm{E}-03$ & $0.00 \mathrm{E}+00$ \\
\hline$b^{3} P_{1}-a^{5} D_{2}$ & 0.2048 & $1.08 \mathrm{E}-02$ & $3.17 \mathrm{E}-01$ \\
\hline$b^{3} P_{1}-a^{5} D_{1}$ & 0.2056 & $9.35 \mathrm{E}-03$ & 4.91E-05 \\
\hline$b^{3} P_{1}-a^{5} D_{0}$ & 0.2060 & $0.00 \mathrm{E}+00$ & $4.32 \mathrm{E}-02$ \\
\hline$b^{3} P_{1}-a^{3} P_{2}$ & 0.3314 & $1.00 \mathrm{E}+00$ & $1.06 \mathrm{E}-02$ \\
\hline$b^{3} P_{1}-a^{3} P_{1}$ & 0.3462 & $3.01 \mathrm{E}-01$ & $1.61 \mathrm{E}-04$ \\
\hline$b^{3} P_{1}-a^{3} P_{0}$ & 0.3525 & $0.00 \mathrm{E}+00$ & $6.96 \mathrm{E}-06$ \\
\hline$b^{3} P_{1}-a^{3} F_{3}$ & 0.3587 & 6.07E-02 & $0.00 \mathrm{E}+00$ \\
\hline$b^{3} P_{1}-a^{3} F_{2}$ & 0.3608 & $3.48 \mathrm{E}-02$ & $2.00 \mathrm{E}-04$ \\
\hline$b^{3} P_{1}-a^{3} G_{3}$ & 0.4093 & $4.61 \mathrm{E}-04$ & $0.00 \mathrm{E}+00$ \\
\hline$b^{3} P_{1}-a^{3} D_{2}$ & 0.5302 & $2.62 \mathrm{E}-02$ & $1.59 \mathrm{E}-03$ \\
\hline$b^{3} P_{1}-a^{3} D_{1}$ & 0.5305 & $1.74 \mathrm{E}-01$ & 7.49E-02 \\
\hline$b^{3} P_{1}-a^{3} D_{3}$ & 0.5342 & $1.89 \mathrm{E}-01$ & $0.00 \mathrm{E}+00$ \\
\hline$b^{3} P_{1}-a^{1} S_{0}$ & 0.6773 & $0.00 \mathrm{E}+00$ & $6.29 \mathrm{E}-02$ \\
\hline$b^{3} P_{1}-a^{1} D_{2}$ & 0.7260 & 2.97E-04 & $5.14 \mathrm{E}-02$ \\
\hline$b^{3} P_{1}-a^{1} F_{3}$ & 1.4970 & $1.89 \mathrm{E}-05$ & $0.00 \mathrm{E}+00$ \\
\hline$b^{3} P_{1}-b^{3} P_{0}$ & 23.3155 & $0.00 \mathrm{E}+00$ & $1.42 \mathrm{E}-03$ \\
\hline$b^{3} P_{2}-a^{5} D_{4}$ & 0.1984 & $6.68 \mathrm{E}-05$ & $0.00 \mathrm{E}+00$ \\
\hline$b^{3} P_{2}-a^{5} D_{3}$ & 0.2001 & $3.43 \mathrm{E}-03$ & $2.05 \mathrm{E}-01$ \\
\hline$b^{3} P_{2}-a^{5} D_{2}$ & 0.2013 & $2.43 \mathrm{E}-04$ & $3.00 \mathrm{E}-04$ \\
\hline$b^{3} P_{2}-a^{5} D_{1}$ & 0.2021 & $5.26 \mathrm{E}-03$ & $1.57 \mathrm{E}-02$ \\
\hline$b^{3} P_{2}-a^{5} D_{0}$ & 0.2025 & $4.46 \mathrm{E}-03$ & $0.00 \mathrm{E}+00$ \\
\hline$b^{3} P_{2}-a^{3} P_{2}$ & 0.3225 & $4.57 \mathrm{E}-01$ & $8.91 \mathrm{E}-05$ \\
\hline$b^{3} P_{2}-a^{3} P_{1}$ & 0.3364 & 4.95E-01 & $2.09 \mathrm{E}-03$ \\
\hline$b^{3} P_{2}-a^{3} P_{0}$ & 0.3424 & $2.34 \mathrm{E}-01$ & $0.00 \mathrm{E}+00$ \\
\hline$b^{3} P_{2}-a^{3} F_{4}$ & 0.3454 & 7.79E-02 & $0.00 \mathrm{E}+00$ \\
\hline$b^{3} P_{2}-a^{3} F_{3}$ & 0.3483 & $1.87 \mathrm{E}-02$ & $1.32 \mathrm{E}-03$ \\
\hline
\end{tabular}


Table 6. continued

\begin{tabular}{|c|c|c|c|}
\hline Transition & $\lambda(\mathrm{obs} ; \mu)$ & $A(\mathrm{E} 2)$ & $A(\mathrm{M} 1)$ \\
\hline$b^{3} P_{2}-a^{3} F_{2}$ & 0.3502 & $1.12 \mathrm{E}-02$ & $2.13 \mathrm{E}-05$ \\
\hline$b^{3} P_{2}-a^{3} H_{4}$ & 0.3341 & $2.10 \mathrm{E}-02$ & $0.00 \mathrm{E}+00$ \\
\hline$b^{3} P_{2}-a^{3} G_{4}$ & 0.3926 & $1.73 \mathrm{E}-03$ & $0.00 \mathrm{E}+00$ \\
\hline$b^{3} P_{2}-a^{3} G_{3}$ & 0.3957 & 1.62E-03 & $2.53 \mathrm{E}-04$ \\
\hline$b^{3} P_{2}-a^{1} G_{4}$ & 0.5121 & $4.95 \mathrm{E}-04$ & $0.00 \mathrm{E}+00$ \\
\hline$b^{3} P_{2}-a^{3} D_{2}$ & 0.5077 & $1.70 \mathrm{E}-01$ & $1.98 \mathrm{E}-02$ \\
\hline$b^{3} P_{2}-a^{3} D_{1}$ & 0.5080 & $4.41 \mathrm{E}-02$ & $1.99 \mathrm{E}-02$ \\
\hline$b^{3} P_{2}-a^{3} D_{3}$ & 0.5114 & $2.50 \mathrm{E}-01$ & $7.09 \mathrm{E}-02$ \\
\hline$b^{3} P_{2}-a^{1} S_{0}$ & 0.6410 & $2.14 \mathrm{E}-04$ & $0.00 \mathrm{E}+00$ \\
\hline$b^{3} P_{2}-a^{1} D_{2}$ & 0.6845 & $6.50 \mathrm{E}-04$ & $1.27 \mathrm{E}-01$ \\
\hline$b^{3} P_{2}-a^{1} F_{3}$ & 1.3306 & 3.98E-08 & $3.61 \mathrm{E}-04$ \\
\hline$b^{3} P_{2}-b^{3} P_{0}$ & 7.9095 & $1.88 \mathrm{E}-08$ & $0.00 \mathrm{E}+00$ \\
\hline$b^{3} P_{2}-b^{3} P_{1}$ & 11.9703 & 3.57E-09 & $7.82 \mathrm{E}-03$ \\
\hline$b^{3} F_{2}-a^{5} D_{4}$ & 0.1993 & $1.05 \mathrm{E}-04$ & $0.00 \mathrm{E}+00$ \\
\hline$b^{3} F_{2}-a^{5} D_{3}$ & 0.2010 & $5.72 \mathrm{E}-04$ & $1.12 \mathrm{E}-02$ \\
\hline$b^{3} F_{2}-a^{5} D_{2}$ & 0.2022 & 3.88E-04 & $2.64 \mathrm{E}-02$ \\
\hline$b^{3} F_{2}-a^{5} D_{1}$ & 0.2030 & $4.64 \mathrm{E}-04$ & $1.24 \mathrm{E}-02$ \\
\hline$b^{3} F_{2}-a^{5} D_{0}$ & 0.2034 & 3.91E-04 & $0.00 \mathrm{E}+00$ \\
\hline$b^{3} F_{2}-a^{3} P_{2}$ & 0.3249 & $3.99 \mathrm{E}-03$ & $1.64 \mathrm{E}-04$ \\
\hline$b^{3} F_{2}-a^{3} P_{1}$ & 0.3390 & $9.23 \mathrm{E}-02$ & $1.50 \mathrm{E}-04$ \\
\hline$b^{3} F_{2}-a^{3} P_{0}$ & 0.3451 & $5.46 \mathrm{E}-02$ & $0.00 \mathrm{E}+00$ \\
\hline$b^{3} F_{2}-a^{3} F_{4}$ & 0.3482 & $2.51 \mathrm{E}-02$ & $0.00 \mathrm{E}+00$ \\
\hline$b^{3} F_{2}-a^{3} F_{3}$ & 0.3511 & 1.69E-01 & $6.97 \mathrm{E}-02$ \\
\hline$b^{3} F_{2}-a^{3} F_{2}$ & 0.3530 & $5.49 \mathrm{E}-01$ & $1.22 \mathrm{E}-04$ \\
\hline$b^{3} F_{2}-a^{3} H_{4}$ & 0.3367 & $2.05 \mathrm{E}+00$ & $0.00 \mathrm{E}+00$ \\
\hline$b^{3} F_{2}-a^{3} G_{4}$ & 0.3961 & 5.97E-02 & $0.00 \mathrm{E}+00$ \\
\hline$b^{3} F_{2}-a^{3} G_{3}$ & 0.3993 & $6.90 \mathrm{E}-01$ & $9.54 \mathrm{E}-02$ \\
\hline$b^{3} F_{2}-a^{1} G_{4}$ & 0.5182 & $1.56 \mathrm{E}-03$ & $0.00 \mathrm{E}+00$ \\
\hline$b^{3} F_{2}-a^{3} D_{2}$ & 0.5136 & $3.16 \mathrm{E}-04$ & $1.61 \mathrm{E}-01$ \\
\hline$b^{3} F_{2}-a^{3} D_{1}$ & 0.5139 & $5.31 \mathrm{E}-03$ & 7.67E-02 \\
\hline$b^{3} F_{2}-a^{3} D_{3}$ & 0.5174 & $1.37 \mathrm{E}-03$ & $1.53 \mathrm{E}-02$ \\
\hline$b^{3} F_{2}-a^{1} S_{0}$ & 0.6505 & $3.96 \mathrm{E}-05$ & $0.00 \mathrm{E}+00$ \\
\hline$b^{3} F_{2}-a^{1} D_{2}$ & 0.6954 & $2.79 \mathrm{E}-05$ & $1.03 \mathrm{E}-02$ \\
\hline$b^{3} F_{2}-a^{1} F_{3}$ & 1.3721 & $3.80 \mathrm{E}-06$ & $1.14 \mathrm{E}-01$ \\
\hline$b^{3} F_{2}-b^{3} P_{0}$ & 9.6441 & 3.53E-08 & $0.00 \mathrm{E}+00$ \\
\hline$b^{3} F_{2}-b^{3} P_{1}$ & 16.4474 & $2.94 \mathrm{E}-09$ & $1.05 \mathrm{E}-05$ \\
\hline$b^{3} F_{3}-a^{5} D_{4}$ & 0.1988 & $2.03 \mathrm{E}-03$ & $8.36 \mathrm{E}-03$ \\
\hline$b^{3} F_{3}-a^{5} D_{3}$ & 0.2006 & $1.32 \mathrm{E}-03$ & 6.19E-02 \\
\hline$b^{3} F_{3}-a^{5} D_{2}$ & 0.2018 & $1.09 \mathrm{E}-05$ & $2.41 \mathrm{E}-02$ \\
\hline$b^{3} F_{3}-a^{5} D_{1}$ & 0.2026 & $8.42 \mathrm{E}-04$ & $0.00 \mathrm{E}+00$ \\
\hline$b^{3} F_{3}-a^{3} P_{2}$ & 0.3237 & $5.56 \mathrm{E}-02$ & $1.77 \mathrm{E}-05$ \\
\hline$b^{3} F_{3}-a^{3} P_{1}$ & 0.3378 & $1.08 \mathrm{E}-01$ & $0.00 \mathrm{E}+00$ \\
\hline$b^{3} F_{3}-a^{3} F_{4}$ & 0.3468 & $1.37 \mathrm{E}-01$ & $6.96 \mathrm{E}-02$ \\
\hline$b^{3} F_{3}-a^{3} F_{3}$ & 0.3497 & $5.20 \mathrm{E}-01$ & $1.39 \mathrm{E}-03$ \\
\hline$b^{3} F_{3}-a^{3} F_{2}$ & 0.3516 & $1.77 \mathrm{E}-01$ & $4.24 \mathrm{E}-02$ \\
\hline$b^{3} F_{3}-a^{3} H_{5}$ & 0.3334 & $1.95 \mathrm{E}+00$ & $0.00 \mathrm{E}+00$ \\
\hline$b^{3} F_{3}-a^{3} H_{4}$ & 0.3354 & $6.74 \mathrm{E}-02$ & $3.65 \mathrm{E}-03$ \\
\hline$b^{3} F_{3}-a^{3} G_{5}$ & 0.3886 & 3.00E-02 & $0.00 \mathrm{E}+00$ \\
\hline$b^{3} F_{3}-a^{3} G_{4}$ & 0.3944 & $6.62 \mathrm{E}-01$ & 4.57E-03 \\
\hline$b^{3} F_{3}-a^{3} G_{3}$ & 0.3976 & $8.60 \mathrm{E}-02$ & $1.34 \mathrm{E}-01$ \\
\hline$b^{3} F_{3}-a^{1} G_{4}$ & 0.5152 & $2.16 \mathrm{E}-03$ & 2.00E-03 \\
\hline$b^{3} F_{3}-a^{3} D_{2}$ & 0.5108 & $3.66 \mathrm{E}-03$ & $8.79 \mathrm{E}-05$ \\
\hline$b^{3} F_{3}-a^{3} D_{1}$ & 0.5110 & $1.16 \mathrm{E}-03$ & $0.00 \mathrm{E}+00$ \\
\hline$b^{3} F_{3}-a^{3} D_{3}$ & 0.5145 & $8.85 \mathrm{E}-04$ & $1.19 \mathrm{E}-01$ \\
\hline$b^{3} F_{3}-a^{1} D_{2}$ & 0.6901 & $2.48 \mathrm{E}-04$ & $3.25 \mathrm{E}-02$ \\
\hline
\end{tabular}

Table 6. continued

\begin{tabular}{|c|c|c|c|}
\hline Transition & $\lambda(\mathrm{obs} ; \mu)$ & $A(\mathrm{E} 2)$ & $A(\mathrm{M} 1)$ \\
\hline${ }^{3} F_{3}-a^{1} F_{3}$ & 1.3517 & $1.29 \mathrm{E}-06$ & $7.15 \mathrm{E}-03$ \\
\hline$b^{3} F_{3}-b^{3} P_{1}$ & 13.9218 & 8.37E-09 & $0.00 \mathrm{E}+00$ \\
\hline$b^{3} F_{3}-b^{3} P_{2}$ & 85.3971 & $1.77 \mathrm{E}-12$ & $5.16 \mathrm{E}-07$ \\
\hline$b^{3} F_{3}-b^{3} F_{2}$ & 90.6618 & $3.35 \mathrm{E}-13$ & $3.40 \mathrm{E}-05$ \\
\hline$b^{3} F_{4}-a^{5} D_{4}$ & 0.1989 & $8.29 \mathrm{E}-03$ & $1.04 \mathrm{E}-01$ \\
\hline$b^{3} F_{4}-a^{5} D_{3}$ & 0.2006 & $1.07 \mathrm{E}-03$ & $2.24 \mathrm{E}-02$ \\
\hline$b^{3} F_{4}-a^{5} D_{2}$ & 0.2019 & $9.86 \mathrm{E}-04$ & $0.00 \mathrm{E}+00$ \\
\hline$b^{3} F_{4}-a^{3} P_{2}$ & 0.3239 & $1.86 \mathrm{E}-01$ & $0.00 \mathrm{E}+00$ \\
\hline$b^{3} F_{4}-a^{3} F_{4}$ & 0.3471 & 7.37E-01 & $4.75 \mathrm{E}-03$ \\
\hline$b^{3} F_{4}-a^{3} F_{3}$ & 0.3499 & $1.53 \mathrm{E}-01$ & $5.02 \mathrm{E}-02$ \\
\hline$b^{3} F_{4}-a^{3} H_{6}$ & 0.3309 & $1.97 \mathrm{E}+00$ & $0.00 \mathrm{E}+00$ \\
\hline$b^{3} F_{4}-a^{3} F_{2}$ & 0.3519 & $6.44 \mathrm{E}-03$ & $0.00 \mathrm{E}+00$ \\
\hline$b^{3} F_{4}-a^{3} H_{5}$ & 0.3336 & $6.35 \mathrm{E}-02$ & $6.89 \mathrm{E}-04$ \\
\hline$b^{3} F_{4}-a^{3} H_{4}$ & 0.3356 & $3.78 \mathrm{E}-02$ & $6.18 \mathrm{E}-06$ \\
\hline$b^{3} F_{4}-a^{3} G_{5}$ & 0.3888 & $7.55 \mathrm{E}-01$ & $1.27 \mathrm{E}-01$ \\
\hline$b^{3} F_{4}-a^{3} G_{4}$ & 0.3947 & $5.68 \mathrm{E}-02$ & $8.78 \mathrm{E}-02$ \\
\hline$b^{3} F_{4}-a^{3} G_{3}$ & 0.3979 & $1.29 \mathrm{E}-03$ & $5.51 \mathrm{E}-03$ \\
\hline$b^{3} F_{4}-a^{1} G_{4}$ & 0.5157 & $2.02 \mathrm{E}-04$ & $4.00 \mathrm{E}-03$ \\
\hline$b^{3} F_{4}-a^{3} D_{2}$ & 0.5113 & 8.77E-04 & $0.00 \mathrm{E}+00$ \\
\hline$b^{3} F_{4}-a^{3} D_{3}$ & 0.5150 & $6.26 \mathrm{E}-03$ & $9.12 \mathrm{E}-02$ \\
\hline$b^{3} F_{4}-a^{1} I_{6}$ & 0.5020 & 2.19E-04 & $0.00 \mathrm{E}+00$ \\
\hline$b^{3} F_{4}-a^{1} D_{2}$ & 0.6910 & $1.87 \mathrm{E}-04$ & $0.00 \mathrm{E}+00$ \\
\hline$b^{3} F_{4}-a^{1} F_{3}$ & 1.3552 & $1.89 \mathrm{E}-05$ & $6.68 \mathrm{E}-02$ \\
\hline$b^{1} G_{4}-a^{5} D_{4}$ & 0.1748 & $1.46 \mathrm{E}-05$ & $1.12 \mathrm{E}-04$ \\
\hline$b^{1} G_{4}-a^{5} D_{3}$ & 0.1761 & $1.27 \mathrm{E}-05$ & $2.31 \mathrm{E}-05$ \\
\hline$b^{1} G_{4}-a^{5} D_{2}$ & 0.1770 & $1.32 \mathrm{E}-05$ & $0.00 \mathrm{E}+00$ \\
\hline$b^{1} G_{4}-a^{3} P_{2}$ & 0.2644 & $1.66 \mathrm{E}-03$ & $0.00 \mathrm{E}+00$ \\
\hline$b^{1} G_{4}-a^{3} F_{4}$ & 0.2796 & $4.33 \mathrm{E}-04$ & 4.53E-02 \\
\hline$b^{1} G_{4}-a^{3} F_{3}$ & 0.2815 & $5.74 \mathrm{E}-04$ & 3.39E-02 \\
\hline$b^{1} G_{4}-a^{3} H_{6}$ & 0.2690 & $9.78 \mathrm{E}-05$ & $0.00 \mathrm{E}+00$ \\
\hline$b^{1} G_{4}-a^{3} F_{2}$ & 0.2828 & $7.81 \mathrm{E}-04$ & $0.00 \mathrm{E}+00$ \\
\hline$b^{1} G_{4}-a^{3} H_{5}$ & 0.2708 & $2.79 \mathrm{E}-06$ & $7.59 \mathrm{E}-02$ \\
\hline$b^{1} G_{4}-a^{3} H_{4}$ & 0.2722 & 6.01E-03 & $1.05 \mathrm{E}-01$ \\
\hline$b^{1} G_{4}-a^{3} G_{5}$ & 0.3062 & $5.85 \mathrm{E}-03$ & $1.58 \mathrm{E}-01$ \\
\hline$b^{1} G_{4}-a^{3} G_{4}$ & 0.3098 & $8.41 \mathrm{E}-04$ & $1.23 \mathrm{E}-02$ \\
\hline$b^{1} G_{4}-a^{3} G_{3}$ & 0.3117 & $9.87 \mathrm{E}-04$ & $1.53 \mathrm{E}-01$ \\
\hline$b^{1} G_{4}-a^{1} G_{4}$ & 0.3797 & $2.44 \mathrm{E}-01$ & $2.86 \mathrm{E}-05$ \\
\hline$b^{1} G_{4}-a^{3} D_{2}$ & 0.3773 & 8.53E-04 & $0.00 \mathrm{E}+00$ \\
\hline$b^{1} G_{4}-a^{3} D_{3}$ & 0.3793 & $1.27 \mathrm{E}-03$ & $6.52 \mathrm{E}-04$ \\
\hline$b^{1} G_{4}-a^{1} I_{6}$ & 0.3722 & $2.05 \mathrm{E}+00$ & $0.00 \mathrm{E}+00$ \\
\hline$b^{1} G_{4}-a^{1} D_{2}$ & 0.4669 & $2.32 \mathrm{E}-02$ & $0.00 \mathrm{E}+00$ \\
\hline$b^{1} G_{4}-a^{1} F_{3}$ & 0.6981 & $5.73 \mathrm{E}-02$ & $1.57 \mathrm{E}-03$ \\
\hline$b^{1} G_{4}-b^{3} P_{2}$ & 1.4686 & $2.38 \mathrm{E}-06$ & $0.00 \mathrm{E}+00$ \\
\hline$b^{1} G_{4}-b^{3} F_{2}$ & 1.4211 & $3.13 \mathrm{E}-07$ & $0.00 \mathrm{E}+00$ \\
\hline$b^{1} G_{4}-b^{3} F_{3}$ & 1.4437 & $2.31 \mathrm{E}-05$ & $1.84 \mathrm{E}-02$ \\
\hline$b^{1} G_{4}-b^{3} F_{4}$ & 1.4398 & $1.68 \mathrm{E}-06$ & $3.15 \mathrm{E}-02$ \\
\hline$b^{1} D_{2}-a^{5} D_{4}$ & 0.1298 & $1.22 \mathrm{E}-04$ & $0.00 \mathrm{E}+00$ \\
\hline$b^{1} D_{2}-a^{5} D_{3}$ & 0.1305 & $1.54 \mathrm{E}-07$ & $2.93 \mathrm{E}-06$ \\
\hline$b^{1} D_{2}-a^{5} D_{2}$ & 0.1311 & $4.88 \mathrm{E}-05$ & $1.33 \mathrm{E}-06$ \\
\hline$b^{1} D_{2}-a^{5} D_{1}$ & 0.1314 & $2.27 \mathrm{E}-06$ & $2.85 \mathrm{E}-06$ \\
\hline$b^{1} D_{2}-a^{5} D_{0}$ & 0.1315 & $6.00 \mathrm{E}-05$ & $0.00 \mathrm{E}+00$ \\
\hline$b^{1} D_{2}-a^{3} P_{2}$ & 0.1735 & 3.61E-03 & 2.40E-02 \\
\hline$b^{1} D_{2}-a^{3} P_{1}$ & 0.1774 & $2.51 \mathrm{E}-04$ & $1.01 \mathrm{E}-02$ \\
\hline$b^{1} D_{2}-a^{3} P_{0}$ & 0.1791 & $2.37 \mathrm{E}-02$ & $0.00 \mathrm{E}+00$ \\
\hline$b^{1} D_{2}-a^{3} F_{4}$ & 0.1799 & $2.04 \mathrm{E}-01$ & $0.00 \mathrm{E}+00$ \\
\hline
\end{tabular}


Table 6. continued

\begin{tabular}{lccc}
\hline Transition & $\lambda(\mathrm{obs} ; \mu)$ & $A(\mathrm{E} 2)$ & $A(\mathrm{M} 1)$ \\
\hline$b^{1} D_{2}-a^{3} F_{3}$ & 0.1807 & $3.35 \mathrm{E}-04$ & $3.33 \mathrm{E}-03$ \\
$b^{1} D_{2}-a^{3} F_{2}$ & 0.1812 & $2.57 \mathrm{E}-02$ & $6.73 \mathrm{E}-04$ \\
$b^{1} D_{2}-a^{3} H_{4}$ & 0.1768 & $8.97 \mathrm{E}-02$ & $0.00 \mathrm{E}+00$ \\
$b^{1} D_{2}-a^{3} G_{4}$ & 0.1919 & $1.31 \mathrm{E}-03$ & $0.00 \mathrm{E}+00$ \\
$b^{1} D_{2}-a^{3} G_{3}$ & 0.1927 & $1.24 \mathrm{E}-03$ & $1.35 \mathrm{E}-06$ \\
$b^{1} D_{2}-a^{1} G_{4}$ & 0.2166 & $1.44 \mathrm{E}+01$ & $0.00 \mathrm{E}+00$ \\
$b^{1} D_{2}-a^{3} D_{2}$ & 0.2159 & $1.17 \mathrm{E}-01$ & $4.82 \mathrm{E}-02$ \\
$b^{1} D_{2}-a^{3} D_{1}$ & 0.2159 & $1.82 \mathrm{E}-05$ & $2.74 \mathrm{E}-01$ \\
$b^{1} D_{2}-a^{3} D_{3}$ & 0.2165 & $1.01 \mathrm{E}-03$ & $2.94 \mathrm{E}-01$ \\
$b^{1} D_{2}-a^{1} S_{0}$ & 0.2368 & $1.09 \mathrm{E}+00$ & $0.00 \mathrm{E}+00$ \\
$b^{1} D_{2}-a^{1} D_{2}$ & 0.2425 & $4.73 \mathrm{E}+00$ & $2.32 \mathrm{E}-03$ \\
$b^{1} D_{2}-a^{1} F_{3}$ & 0.2928 & $9.84 \mathrm{E}-01$ & $1.74 \mathrm{E}-03$ \\
$b^{1} D_{2}-b^{3} P_{0}$ & 0.3585 & $3.68 \mathrm{E}-04$ & $0.00 \mathrm{E}+00$ \\
$b^{1} D_{2}-b^{3} P_{1}$ & 0.3641 & $3.13 \mathrm{E}-06$ & $2.50 \mathrm{E}-02$ \\
$b^{1} D_{2}-b^{3} P_{2}$ & 0.3755 & $1.08 \mathrm{E}-04$ & $6.72 \mathrm{E}-02$ \\
$b^{1} D_{2}-b^{3} F_{2}$ & 0.3723 & $1.26 \mathrm{E}-03$ & $3.80 \mathrm{E}-02$ \\
$b^{1} D_{2}-b^{3} F_{3}$ & 0.3738 & $2.25 \mathrm{E}-03$ & $5.62 \mathrm{E}-02$ \\
$b^{1} D_{2}-b^{3} F_{4}$ & 0.3736 & $4.10 \mathrm{E}-03$ & $0.00 \mathrm{E}+00$ \\
$b^{1} D_{2}-b^{1} G_{4}$ & 0.5045 & $5.67 \mathrm{E}-01$ & $0.00 \mathrm{E}+00$ \\
$b^{1} S_{0}-a^{5} D_{2}$ & 0.0936 & $3.45 \mathrm{E}-03$ & $0.00 \mathrm{E}+00$ \\
$b^{1} S_{0}-a^{5} D_{1}$ & 0.0937 & $0.00 \mathrm{E}+00$ & $1.58 \mathrm{E}-04$ \\
$b^{1} S_{0}-a^{3} P_{2}$ & 0.1133 & $1.03 \mathrm{E}-01$ & $0.00 \mathrm{E}+00$ \\
$b^{1} S_{0}-a^{3} P_{1}$ & 0.1150 & $0.00 \mathrm{E}+00$ & $2.47 \mathrm{E}-01$ \\
$b^{1} S_{0}-a^{3} F_{2}$ & 0.1166 & $4.77 \mathrm{E}-01$ & $0.00 \mathrm{E}+00$ \\
$b^{1} S_{0}-a^{3} D_{2}$ & 0.1300 & $1.76 \mathrm{E}+00$ & $0.00 \mathrm{E}+00$ \\
$b^{1} S_{0}-a^{3} D_{1}$ & 0.1300 & $0.00 \mathrm{E}+00$ & $1.51 \mathrm{E}-03$ \\
$b^{1} S_{0}-a^{1} D_{2}$ & 0.1392 & $8.57 \mathrm{E}+01$ & $0.00 \mathrm{E}+00$ \\
$b^{1} S_{0}-b^{3} P_{1}$ & 0.1722 & $0.00 \mathrm{E}+00$ & $3.35 \mathrm{E}+00$ \\
$b^{1} S_{0}-b^{3} P_{2}$ & 0.1748 & $5.76 \mathrm{E}-02$ & $0.00 \mathrm{E}+00$ \\
$b^{1} S_{0}-b^{3} F_{2}$ & 0.1741 & $8.62 \mathrm{E}-03$ & $0.00 \mathrm{E}+00$ \\
$b^{1} S_{0}-b^{1} D_{2}$ & 0.3269 & $1.53 \mathrm{E}+01$ & $0.00 \mathrm{E}+00$ \\
\hline & & & \\
\hline
\end{tabular}

Table 7. Comparison of magnetic dipole transition probabilities (P - present; G - Garstang) in units of $\mathrm{s}^{-1}$. All levels have prefix 'a' (see Table 5)

\begin{tabular}{|c|c|c|}
\hline Transition & $A(\mathrm{M} 1, \mathrm{P})$ & $A(\mathrm{M} 1, \mathrm{G})$ \\
\hline${ }^{5} D_{3}-{ }^{5} D_{4}$ & $2.87(-3)$ & $2.80(-3)$ \\
\hline${ }^{5} D_{2}-{ }^{5} D_{3}$ & $1.79(-3)$ & $1.80(-3)$ \\
\hline${ }^{5} D_{1}-{ }^{5} D_{2}$ & $6.82(-4)$ & $6.70(-4)$ \\
\hline${ }^{5} D_{1}-{ }^{5} D_{2}$ & $6.82(-4)$ & $6.70(-4)$ \\
\hline${ }^{3} P_{2}-{ }^{5} D_{3}$ & $5.09(-1)$ & $4.00(-1)$ \\
\hline${ }^{3} P_{2}-{ }^{5} D_{1}$ & $4.91(-2)$ & $3.80(-2)$ \\
\hline${ }^{3} P_{1}-{ }^{5} D_{2}$ & $6.32(-1)$ & $5.30(-1)$ \\
\hline${ }^{3} P_{1}-{ }^{5} D_{0}$ & $1.10(-1)$ & $9.10(-2)$ \\
\hline${ }^{3} P_{1}-{ }^{3} P_{2}$ & $4.77(-2)$ & $4.70(-2)$ \\
\hline${ }^{3} P_{0}-{ }^{5} D_{1}$ & $8.13(-1)$ & $6.70(-1)$ \\
\hline${ }^{3} P_{0}-{ }^{3} P_{1}$ & $7.54(-3)$ & $7.50(-3)$ \\
\hline${ }^{3} F_{4}-{ }^{5} D_{4}$ & $4.30(-1)$ & $4.40(-1)$ \\
\hline${ }^{3} F_{4}-{ }^{5} D_{3}$ & $8.23(-2)$ & $8.10(-2)$ \\
\hline${ }^{3} F_{3}-{ }^{5} D_{3}$ & $2.32(-1)$ & $2.70(-1)$ \\
\hline${ }^{3} F_{3}-{ }^{5} D_{2}$ & $8.13(-2)$ & $8.70(-2)$ \\
\hline${ }^{3} F_{2}-{ }^{5} D_{3}$ & $2.56(-2)$ & $2.60(-2)$ \\
\hline${ }^{3} F_{2}-{ }^{5} D_{2}$ & $9.04(-2)$ & $1.00(-1)$ \\
\hline${ }^{3} F_{2}-{ }^{5} D_{1}$ & $4.41(-2)$ & $4.90(-2)$ \\
\hline${ }^{3} G_{5}-{ }^{3} F_{4}$ & $7.94(-3)$ & $2.30(-2)$ \\
\hline${ }^{3} G_{5}-{ }^{3} H_{6}$ & $4.11(-2)$ & $4.50(-2)$ \\
\hline${ }^{3} G_{5}-{ }^{3} H_{5}$ & $2.89(-2)$ & $2.90(-2)$ \\
\hline${ }^{3} G_{4}-{ }^{5} D_{4}$ & $2.88(-3)$ & $1.90(-2)$ \\
\hline${ }^{3} G_{4}-{ }^{5} D_{3}$ & $9.41(-4)$ & $3.70(-3)$ \\
\hline${ }^{3} G_{4}-{ }^{3} F_{4}$ & $8.08(-3)$ & $3.70(-2)$ \\
\hline${ }^{3} G_{4}-{ }^{3} H_{4}$ & $4.58(-2)$ & $2.50(-2)$ \\
\hline${ }^{3} G_{3}-{ }^{3} F_{3}$ & $1.60(-2)$ & $3.90(-2)$ \\
\hline${ }^{3} G_{3}-{ }^{3} H_{4}$ & $3.68(-2)$ & $4.40(-2)$ \\
\hline${ }^{1} G_{4}-{ }^{3} F_{4}$ & $1.26(-1)$ & $2.30(-1)$ \\
\hline${ }^{1} G_{4}-{ }^{3} F_{3}$ & $9.87(-2)$ & $1.20(-1)$ \\
\hline${ }^{1} G_{4}-{ }^{3} H_{5}$ & $2.46(-1)$ & $2.00(-1)$ \\
\hline${ }^{1} G_{4}-{ }^{3} H_{4}$ & $2.15(-1)$ & $8.10(-2)$ \\
\hline${ }^{3} D_{2}-{ }^{5} D_{3}$ & $2.59(-2)$ & $2.70(-2)$ \\
\hline${ }^{3} D_{2}-{ }^{5} D_{2}$ & $9.49(-2)$ & $1.10(-1)$ \\
\hline${ }^{3} D_{2}-{ }^{5} D_{1}$ & $8.31(-2)$ & $9.50(-2)$ \\
\hline${ }^{3} D_{2}-{ }^{3} P_{2}$ & $3.98(-2)$ & $6.60(-2)$ \\
\hline${ }^{3} D_{1}-{ }^{5} D_{1}$ & $1.24(-2)$ & $1.50(-2)$ \\
\hline${ }^{3} D_{1}-{ }^{5} D_{0}$ & $1.10(-1)$ & $1.30(-1)$ \\
\hline${ }^{3} D_{1}-{ }^{3} P_{2}$ & $1.18(-2)$ & $1.90(-2)$ \\
\hline${ }^{3} D_{1}-{ }^{3} P_{1}$ & $4.25(-2)$ & $8.50(-2)$ \\
\hline${ }^{3} D_{1}-{ }^{3} P_{0}$ & $1.17(-2)$ & $2.30(-2)$ \\
\hline${ }^{3} D_{3}-{ }^{5} D_{4}$ & $1.96(-1)$ & $2.30(-1)$ \\
\hline${ }^{3} D_{3}-{ }^{5} D_{3}$ & $5.56(-2)$ & $4.70(-2)$ \\
\hline${ }^{3} D_{3}-{ }^{5} D_{2}$ & $4.12(-2)$ & $4.40(-2)$ \\
\hline${ }^{3} D_{3}-{ }^{3} P_{2}$ & $3.44(-2)$ & $6.30(-2)$ \\
\hline${ }^{1} I_{6}-{ }^{3} H_{6}$ & $6.73(-2)$ & $8.90(-2)$ \\
\hline${ }^{1} I_{6}-{ }^{3} H_{5}$ & $4.41(-2)$ & $5.80(-2)$ \\
\hline${ }^{1} S_{0}-{ }^{3} P_{1}$ & $1.38(0)$ & $1.50(0)$ \\
\hline${ }^{1} D_{2}-{ }^{3} P_{2}$ & $7.91(-2)$ & $9.60(-2)$ \\
\hline${ }^{1} D_{2}-{ }^{3} P_{1}$ & $2.83(-2)$ & $3.30(-2)$ \\
\hline${ }^{1} D_{2}-{ }^{3} F_{3}$ & $2.25(-1)$ & $2.20(-1)$ \\
\hline${ }^{1} D_{2}-{ }^{3} F_{2}$ & $1.23(-1)$ & $1.20(-1)$ \\
\hline${ }^{1} D_{2}-{ }^{3} D_{1}$ & $4.65(-2)$ & $2.10(-2)$ \\
\hline${ }^{1} D_{2}-{ }^{3} D_{3}$ & $4.51(-2)$ & $2.00(-2)$ \\
\hline${ }^{1} F_{3}-{ }^{3} G_{4}$ & $1.07(-1)$ & $9.80(-2)$ \\
\hline${ }^{1} F_{3}-{ }^{3} D_{2}$ & $3.14(-2)$ & $3.40(-2)$ \\
\hline${ }^{1} F_{3}-{ }^{3} D_{3}$ & $5.36(-2)$ & $6.10(-2)$ \\
\hline
\end{tabular}

